\title{
Cerramientos de tierra en el siglo XVIII según los despachos de Gracia del Consejo de Castilla
}

\author{
Ceferino Caro López ${ }^{1}$ \\ IES Beatriz Galindo, Madrid \\ cefcarolo@yahoo.com
}

RESUMEN: La concesión de cerramiento conseguido por la vía de Gracia proporciona la posibilidad de analizar las motivaciones de quienes los emprendían en el siglo XVIII. El principal objetivo era el de separar legalmente un bien de su uso común para explotarlo en beneficio privado. La intervención capitalista se nota por la inversión necesaria para realizar el cerramiento y la búsqueda de mayor beneficio en el cultivo. Geográficamente los cerramientos se localizan en su mayoría en Andalucía occidental y su objeto es el cultivo de olivo, vid y dehesa.

Palabras Clave: Agricultura; cerramientos; cultivos; propiedad de la tierra; comunales; capitalismo.

\section{Enclosures of Land in XVIII Century According to the Gratia Offices of the Council of Castile}

ABSTRACT: The right of enclosure obtained ex gratia offers the possibility of analyzing the aims of those who undertook that system in the Eighteenth century. Their main goal was to divide with legal permission a public property in order to work it in private interest. The capitalistic intervention shows itself from the investment required to carry out the enclosure and the quest of higher returns from the land. Geographically enclosures are mainly located in Western Andalusia and their aim was to grow olive trees, vine and grassland.

KEY WORDS: Agriculture; enclosures; farming; landownership; commons; capitalism.

1 ORCID iD: http://orcid.org/0000-0003-3412-6333. 
COMO CITAR ESTE ARTICULO/CITATION: Caro López, Ceferino, «Cerramientos de tierra en el siglo XVIII según los despachos de Gracia del Consejo de Castilla)», Hispania, 77/255 (Madrid, 2017): 117-153. doi: 10.3989/hispania.2017.005.

Este trabajo pretende aproximarse cualitativamente a un hecho económico cuantitativo, a saber el proceso de cerramientos de tierras en el siglo XVIII. El conjunto de esas intervenciones es enorme, y requeriría una investigación muy pormenorizada de los fondos documentales; aquí se han tomado en consideración solamente las peticiones de licencia de cerramiento presentadas al Consejo de Castilla por la vía de Gracia por dos motivos básicos: primero, el menor número de casos, que permite comprenderlos en su conjunto y elaborarlos; segundo, que al ser expedientes de gracia las peticiones estaban razonadas y motivadas, lo que hace posible penetrar las razones económicas de quienes promovían los cerramientos, partiendo de las palabras de los mismos interesados ${ }^{2}$. Es muy interesante también notar que el tenor de las peticiones de gracia es prácticamente igual durante el período en que estuvieron prohibidos los cerramientos - de 1748 a 1788 - que cuando estaban permitidos 33 casos registrados ante 1748. En ambos casos, el hecho de que se debiera recurrir a la vía de Gracia indica que o la legislación era insuficiente o que se había llegado al convencimiento de que las decisiones del poder se inclinarían en favor de los promotores sin tomar en consideración los derechos establecidos por las costumbres y por las leyes.

Lo que se intenta aquí no es profundizar en las estructuras agrarias concretas de las zonas mencionadas en este estudio, sino hacer algo de luz sobre las motivaciones de los promotores de cerramientos, es decir buscar el denominador común de las peticiones de gracia por mucho que los lugares de donde procedían tuvieran realidades agrícolas o incluso físicas y climáticas muy distintas. Al no tratarse de informaciones con fines recaudatorios cabe descartar la voluntad de fraude en las fuentes consultadas, lo que no es óbice para que las cuentas de los promotores, cuando las presentaban para motivar sus proyectos, puedan ser erróneas, más fruto de un deseo que de lo realmente alcanzable, ya que la magnificación de los futuros beneficios, incluso no justificada racionalmente, puede ser parte de la actitud del emprendedor al iniciar su proyecto. En este sentido las peticiones analizadas deberían ser aceptables en cuanto a su fiabilidad por lo que se refiere a la opinión de quienes las formulaban. Los que cerraban tierras estaba convencidos de que mejorarían sus beneficios, participando de la perspectiva general del pensamiento de muchos

2 Este trabajo se ha realizado sobre los Decretos de Gracia del Consejo de Castilla para los años 1714-1799 en el Archivo Histórico Nacional, (AHN), Consejos, legajos 1284, 1965, 4478 a 4610 y libros 389 y 830. 
en el siglo XVIII; como ha dicho Allen, «el gran misterio» es saber por qué lo consiguieron ${ }^{3}$.

Desde el punto de vista geográfico destaca el hecho que grueso de los cerramientos por vía de Gracia tuvieron lugar en la Baja Andalucía, con 54 peticiones de 68 registradas, con algunos casos en Extremadura, 9, y son puramente testimoniales - 3 y 2 casos - en Castilla la Vieja y La Mancha respectivamente. Comparando el origen de las peticiones de gracia con los expedientes abiertos en el consejo de Castilla durante el mismo período se nota la misma posición destacada de Andalucía con el 43,9\% de los casos localizados, seguida muy de lejos por Extremadura y Castilla La Vieja (16,67\% de casos ambas) y La Mancha con el 8,94\% de los expedientes. Madrid, Asturias, Murcia, Galicia aparecen con frecuencias que van de $6,1 \%$ al $0,41 \%$ de los casos.

Estos datos tan parciales de las peticiones de gracia coinciden con la visión general de Sebastián Amarilla, para quien se dio «una intensificación sostenida del cultivo sólo en zonas muy reducidas del territorio nacional» mientras que en la España del interior fue una «porción minúscula» de la intensificación de los cultivos ${ }^{4}$.

El término mismo, y uso que hacían de él los contemporáneos, indica la realidad del hecho: desde el léxico medieval español «cerrar» significaba «Cercar, vallar, rodear, acordonar», y «acotar» «poner cotos, señalar los límites o amojonar un terreno con cotos». Luego aunque los términos se tomaran como sinónimos se referían a dos pasos del mismo proceso, como se demuestra por lo expuesto en algunas decisiones de la Cámara: En «el cortijo de El Álamo no tenga efecto el cerramiento hasta que el interesado lo haya cercado»; «no siendo por el medio de construir una tapia de pared que la cierre, y cerque»; «con la obligación de que la cerque de tapia» ${ }^{5}$, pero no se trataba ciertamente de un hecho nuevo. En las peticiones dirigidas a la Cámara se indicaba qué cerramientos ya había desde 1646. Por ejemplo, en Morón: «Hallarse casi cerradas todas la tierras, y monte, con los vallados de las viñas que circundan el cortijo»,o en Ronda: «cercado, y adehesados los dichos terrenos, en la forma, y con los requisitos que en semejantes casos se acostumbra $»^{6}$, dejando entender

3 ALLEN, 2004: 17, 156, 161

4 SEBASTIÁN AMARILLA, 2004: 150-151. Por lo que se refiere a las superficies afectadas, el término fanega de superficie es la referencia genérica usada por los investigadores, Robledo, Bernal, Yun, Gámez... y aquí se abreviará siempre en fs. Se dan sus equivalentes en hectáreas en los casos más significativos. www.juntaandalucia.es/averroes/ceacamiles/ pesos medidas; www.upm.es/ingnieria-agroforestal/; JUAN Y SEVA, 1863; Correspondencia oficial entre las antiguas medidas... de conformidad con la Real Orden del 9 de diciembre de 1852, publicada en la «Gaceta» de Madrid el 28 de dicho mes y año.

5 ALONSO, 1986. AHN Consejos legs. 4577/164, 4588/159, 2404/6. MUÑOZ DE BUSTILLO, 1998.

6 AHN Consejos, legajo 4481/10; 4501/38; 4594/15. 
que se trataba de prácticas tenidas por usuales ${ }^{7}$. Lo que resulta evidente, dada la extensión de algunas de las fincas «cerradas», es que dicho cerramiento no era físico, pues en ciertos casos habría requerido la construcción de tapias de longitud descomunal; se entendía por «cerrada» la heredad «amojonada», es decir aquélla cuyos límites quedaban marcados claramente.

\section{CERRAMientos Y COMUNALES}

Más allá de las tentativas, planteamientos, contradicciones, éxitos y fracasos de la política económica de la Ilustración uno de los afanes indiscutidos de los reformadores dieciochescos se centró en crear o fomentar la figura del labrador acomodado, propietario de una pequeña o mediana extensión que representa al incipiente capitalista rural con todos sus vicios y virtudes ${ }^{8}$, pero la falta de tierra disponible en el mercado llevaba obligatoriamente a una conflictividad rural que Ortega y Sánchez Salazar han señalado, y se pone de manifiesto en las protestas campesinas del Memorial Ajustado ${ }^{9}$.

Era la política ilustrada, fuertemente prevenida contra las formas tradicionales de explotación agrícola y así la habían formulado en sus grandes líneas los principales pensadores teóricos. Por ejemplo, para Ferrer Gorraiz la causa primera del retraso de la agricultura en el reino era el descuido de los propietarios en la explotación de sus tierras; la solución evidente pasaba por racionalizar el uso y disfrute de la propiedad ${ }^{10}$, pensando como Olavide, Campomanes en 1783 o Jovellanos en $1795^{11}$. En opinión de Jovellanos la pobreza

7 En Andalucía frecuentemente los cerramientos seguían a usurpaciones y acababan con la pérdida de derechos comunales. Hacia mediados del dieciocho el $21 \%$ de la superficie de los cortijos sevillanos estaba cerrada. PÉREZ CEBADA, 2007: 333 y 339. En Andalucía la prohibición de cercar de 1687 en el valle del Guadalquivir no se respetaba, e incluso se realizaron cerramientos «más intensamente» después de 1712 (p. 72) BERNAL, 1988: 72

8 AMALRIC, 1985. GARCÍA SANZ y SANZ FERNÁNDEZ, 1988: 55. CONGOST I COLOMER, 2000. YUN CASALILLA, 2002.

9 ORTEGA LÓPEZ, 1989. SÁNCHEZ SALAZAR, 1989. Memorial Ajustado hecho de orden del Consejo... sobre los daños y decadencia que padece la Agricultura, sus motivos y medios para su restablecimiento, y fomento... sobre establecimiento de una Ley Agraria... s.1. s.a. [1771].

10 FERRER GORRAIZ Y BEAUMONT, 1785

11 Para Olavide Andalucía estaba mal cultivada porque había dehesas y monte bajo. Olavide y Jovellanos entendían por actividad ideal la de una propiedad cerrada para impedir que los ganados la invadieran. Los campos abiertos eran uno de los «estorbos» según Jovellanos, debidos a las malas leyes, que habría que derogar por ser atentatorios a la propiedad. Jovellanos, Informe de la Sociedad Económica de esta Corte al Real y Supremo Consejo de Castilla en el expediente de Ley agraria, Madrid, Sancha, 1795, pp. 24-38. Campomanes, Olavide, Jovellanos reservaban el disfrute completo de la tierra al dueño de ella. Otras voces, como 
de los campos españoles se explicaba «porque ha[bía] baldíos, porque las tierras est[aba]n abiertas», y en su Informe sobre la Ley agraria daba gran importancia a la posibilidad de cerrar las fincas particulares. La prohibición de cerrar fincas era «una costumbre bárbara, nacida en tiempos bárbaros» pues limitaba el derecho de propiedad. Sin embargo no eran sólo los intereses de la Mesta los que se oponían a los acotamientos de tierras, porque resulta claro que la superación de los modelos tradicionales de uso del suelo propugnada por los reformadores era un ataque frontal a muchas costumbres y derechos tradicionales de los campesinos e implicaba un empobrecimiento de los menos favorecidos. La política de control primero, y de libertad después, para cerrar tierras se ha de ver por lo tanto también como un episodio de la lucha de clases en el mundo rural. Para Bernal, siguiendo a Artola, el campo vivía en situación de tensión social cuasi permanente, y Robledo Hernández introduce la sospecha de que los implicados en esta confrontación no eran solamente arrendadores y arrendatarios locales sino que entraban en juego los intereses de grupos sociales capaces de hacer presión sobre los organismos del Gobierno; probablemente la política de cerramientos refleje ese juego de intereses ${ }^{12}$.

Una faceta de esta realidad de lucha por la tierra es la de la erosión de los comunales con el fin de conseguir propiedades privadas. Para alcanzar ese objetivo se podían seguir dos caminos distintos aunque el resultado era el mismo: la compraventa de bienes comunes o su usurpación, usurpación que generalmente concluía con una regularización mediante venta al usurpador, y las dos estrategias se reflejan en los expedientes de gracia y se registran con las peticiones dado que ése era el fin de tales acciones.

TABLA 1. Propuestas de venta de tierras comunales para su cerramiento (en fanegas).

\begin{tabular}{|c|c|c|c|c|}
\hline AÑo & LUGAR & TERRENO & SUPERFICIE & DECISIÓN DE LA CÁMARA \\
\hline 1722 & Dos Hermanas & Baldío & 46,5 & Concedida, leg 4484/48 \\
\hline 1725 & Cala & Baldío & $36-40$ & Rechazada, leg 4485/52 \\
\hline 1726 & Vera & Pasto realengo & 615 & Rechazada, leg 4486/9 \\
\hline 1728 & Cuenca & Baldío realengo & 1,5 & Rechazada, leg 4489/69 \\
\hline 1737 & Cala & Repite 1725 & $36-40$ & Concedida, leg 4498/6 \\
\hline
\end{tabular}

Caxa de Leruela, hacían notar el consiguiente empobrecimiento de los vecinos; Floridablanca abogaba por mantener el sistema de «derrota de mieses». BERNAL, 1988. SÁNCHEZ SALAZAR, 2007. CONGOST I COLOMER, 2007. Véanse también BUSTOS RODRÍGUEZ 1989. ANES, 1996: 95 y 98. MUÑOZ DE BUSTILLO, 1998. SANTIAGO BUJALANCE, 2004: 29. YUN CASALILLA, 2002.

12 BERNAL, 1994: 83-84. ROBLEDO HERNÁNDEZ, 1989: 705. También YUN CASALILLA, 1989: 500. 


\begin{tabular}{|c|c|c|c|c|}
\hline AÑo & LUGAR & TERRENO & SUPERFICIE & DECISIÓN DE LA CÁMARA \\
\hline 1753 & Redondela & Vereda & 0,25 & Concedida, leg $4526 / 3$ \\
\hline 1774 & Osuna & Dehesa & 550 & Rechazada, leg $4478 / 15$ \\
\hline 1775 & Valencia Alcántara & Monte & 9 & Concedida, leg 4577/146 \\
\hline 1780 & La Rinconada & Baldío & 600 & Concedida, leg $4595 / 56$ \\
\hline 1787 & Carmona & Baldío & 1.020 & Concedida, leg 4607/43 \\
\hline
\end{tabular}

TABLA 2. Usurpaciones de comunales seguidas de venta y cerramiento (en fanegas).

\begin{tabular}{|c|c|c|c|c|}
\hline AÑO & LUGAR & TIPO DE TERRENO & SUPERFICIE & DECISIÓN DE LA CÁMARA \\
\hline 1723 & Lebrija & Baldío & 4 & Concedida, leg 4484/3 \\
\hline 1726 & Las Cabezas & Baldío & 12 & Rechazada, leg 4486/21 \\
\hline 1727 & Las Cabezas & Repite petición & 12 & Concedida, leg 4487/27 \\
\hline 1789 & Chiclana & Pinar & $i ? \quad$ lib. 830/158 \\
\hline
\end{tabular}

Aunque los casos son pocos indican la innegable realidad de que autoridades locales y Consejo, en el siglo XVIII, estaban dispuestos a no impedir que los bienes comunales pasaran a manos privadas, ya que de los diez expedientes en los que el solicitante proponía adquirir comunales sólo se rechazaron dos y de los tres expedientes en que se había cometido una usurpación dos se regularizaron con la posterior compraventa de las tierras. A lo sumo, de las tablas 1 y 2 , se podrá vislumbrar una cierta tendencia a defender el patrimonio comunal sólo en el primer cuarto del Setecientos, porque a partir de 1728 se reconocen todas las peticiones de privatización de tierras comunes.

En los expedientes de la Cámara no faltan ecos de conflictos entre los suplicantes y el resto de los vecinos a propósito de los cerramientos, fueran o no de comunales, que aparecen en los informes de las autoridades locales al Consejo. Se pueden ver en la acción promovida en Cala por don Álvaro de Castilla para acotar 200 fanegas (73,79 ha): las autoridades del pueblo declaraban que ese cerramiento no habría perjudicado a nadie sino a ciertos vecinos «con pretexto de que cerrándose estas tierras se les embarazaría el paso para otro pedazo del término que tiene la Villa inmediato a ellas, y para usar del agua del río». No parece que la objeción fuera baladí pero el ayuntamiento la minimizaba y la Cámara concedía la gracia solicitada. En cambio no tenían éxito las pretensiones de don Antonio Maraver Ponce de León de cerrar una finca de 100 fanegas «para caza menuda» en Jerez de los Caballeros, denegadas cuando el ayuntamiento hacía valer que las tierras estaban en una dehesa «de pasto y labor y bellota como las demás dehesas de aquel término, 
y se siembra cuando cae a giro [...] por lo que tiene por conveniente se continúe en lo respectivo a al tierra útil de labor, a causa de que con su desmembración se perturbarían los giros de ella en perjuicio del Común» y proponía que se acotara otro terreno que no perjudicara las servidumbres de paso y los turnos de labor. Esa fue la solución aceptada por la Cámara pero se debe notar que en los dos ejemplos mencionados las autoridades locales siguieron un comportamiento completamente opuesto en relación con la defensa de los intereses de sus vecinos.

Son numerosos los casos de intereses privados puestos por encima de los comunes; ejemplar por la claridad de su planteamiento es el del marqués de Villadarias en Antequera en 1751. Se refería a su cortijo de Los Bodoques, «para cuya conservación necesita cerrarle de lo cual no se sigue perjuicios alguno por no comprenderse en él dehesa, ni prado concejil ni público ni de común aprovechamiento», en palabras del peticionario. Afectaba una superficie de 573 fanegas $(345,92$ ha) y producía anualmente 100 arrobas de aceite, bellota por valor de 40 ducados, 100 fanegas de trigo y 50 de cebada. El informe del corregidor era ambiguo y no coincidía exactamente con lo que afirmaba el propietario:

[h]ay comunidad de pastos en él, de que participan recíprocamente todos los vecinos de aquella ciudad, en todo el año por regla común [...]; de cerrar el dicho cortijo se seguirá al marqués la utilidad de hacer sus pastos propios, y no comunicables a los demás vecinos, y por este medio lograr la cría de monte con más facilidad [...] y que atendida la situación de dicho cortijo, y que por el plantío de olivar, y monte con que se halla está reservada en esta parte de la comunicación de pastos, no considera la ciudad que cerrándose el cortijo hará falta por su cortedad para el aprovechamiento común, ni contempla inconveniente ni perjuicio particular.

La Cámara seguía en sus grandes líneas el razonamiento del corregidor pero velaba porque se mantuvieran abiertos los caminos reales que cruzaban la finca. Además encontraba que el marqués estaba justificado en sus pretensiones de no pagar «servicio pecuniario en atención a sus atrasos y servicios propios, y heredados» ${ }^{13}$. Igual de poco transparente parece el caso expuesto en Córdoba en 1734 por don Pedro de Zea y Córdoba, propietario de varias tierras en la Sierra de hasta 3.091 fanegas $(1.892,07 \mathrm{ha})$, entre las que contaba una dehesa de 115 fanegas y 9 celemines $(70,85$ ha) que deseaba acotar, más,

13 Cala, 19/XII/1725, AHN, Consejos, legajo 4485/52; Jerez de los Caballeros, 1/XII/1738, legajo 4499/82; Los Bodoques, 28/VII/1751, legajo 4523/76. Más casos parecidos: Medina Sidonia, 20/II/1775, legajo 4577/164; Burguillos, 14/VI/1780, legajo 4588/159; Dos Hermanas, 18/III/1782, legajo 4592/24; Villanueva del Río, 3/VIII/1782, legajo 4593/61; Castro del Río, 2/X/1786, legajo 4602/77; San Vicente de Cubelas, 12/III/1789, legajo $830 / 59-v$. 
decía él ante la Cámara «se le intenta inquietar y perturbar por varias personas con pretexto de que [...] alzado el fruto deben ser las tierras de los lagares, pastos comunes para los vecinos de dicha ciudad y lugares que con ella tienen comunidad».

El intento tenía todos los visos de ser una ampliación arbitraria de un antiguo privilegio fechado en 1685, pero el ayuntamiento informaba favorablemente y la Cámara le concedía la gracia solicitada tras servicio de 1.875 reales $^{14}$. Leyendo las razones del convento de San Agustín en Santaella se aprecia la misma conflictividad entre propietarios y ayuntamientos: los frailes querían cerrar su cortijo de 180 fanegas (110,18 ha) en Las Praderillas «por introducir los vecinos de la expresada villa, y otros, los ganados a pastar los rastrojos». El ayuntamiento se oponía a esa pretensión pero el parecer del corregidor de Córdoba era exactamente lo contrario de lo que decían los villanos:

No se sigue perjuicio alguna a la villa de Santa Ella, por ser su término de los mayores de aquel Reino, pues se compone de más de cuarenta mil fanegas de tierra de labor, a excepción de montes, y olivares en el cual sólo hay de tres a cuatro mil fanegas de tierra cerradas, y acotadas, y todas las demás son baldías y de aprovechamiento común ${ }^{15}$.

Así que la tendencia a la formación de enclaves de propiedad privada en el ámbito de los bienes comunales se convertía en un hecho y ocurría con el beneplácito del poder ya fuera central ya local. En 1728 en Villanueva del Río don Manuel de las Cuentas cerraba 300 fanegas (178,34 ha) de olivar «de inferior calidad» y la Audiencia de Sevilla informaba del caso: las tierras se habían concedido en fuerza de una real facultad de 1646 para repartir entre los vecinos de la villa «tierras de los montes baldíos» a condición de que se plantaran en los seis años siguientes; ahora bien, de las 300 fanegas en cuestión sólo se había hecho plantío en 100 aranzadas (47,55 ha), por lo que «era por lo mismo creíble que su fin se dirigía principalmente a tener una dehesa de pasto en las tierras fin muy opuesto a el que le habían sido repartidas». Además decía que «si las acotara por su particular utilidad se le quitaría al Común y Público». Esta postura es la que cabría encontrar en las instancias dedicadas a velar por los intereses comunes, y sobre todo la que correspondería a los más altos organismos del Estado. Sin embargo ante las razones de la Audiencia la Cámara proponía como única, floja condición, que el plantío se realizara antes de diez años o de lo contrario «cesar en el cerramiento» ${ }^{16}$.

14 AHN, Consejos, legajo 4495/79, de 30/VI/1734.

15 Se concedió la gracia «sirviendo» con 1.654,5 rs. AHN, Consejos, legajo 4496/29, de $11 / \mathrm{V} / 1735$.

16 «Sirviendo» con 1 ducado/fs. AHN, Consejos, legajo 4593/61, de 3/VIII/1782. 


\section{Plantíos Y DAÑos DEL GANAdo}

La denuncia de los males endémicos del mundo rural no era exclusiva de los teóricos políticos reformadores; en un libro escrito para continuar la historia de Don Quijote, el autor vertía algunos juicios sobre el estado de los campos españoles:

Caminaban divertidos, ya viendo campos eriales, ya advirtiendo tierras mal aprovechadas por la desidia o pobreza de los pueblos; que todo esto y más se halla cuando se camina si se observa y mira con cuidado. [...] Empezóse la conversación común de cortas cosechas, muchos pobres, el ningún cuidado de poner arboledas, construir puentes, allanar caminos $[\ldots]^{17}$.

El diagnóstico literario coincidía con el de los políticos en la denuncia de los pocos cuidados que se ponían en los cultivos, en la falta de infraestructuras y de la escasez de arboledas. Precisamente los plantíos eran una de las preocupaciones de la política ilustrada, y los cerramientos condición necesaria para realizarlos; de hecho la petición de licencias para acotar fincas está ligada estrechamente a la proclamación de leyes de protección y fomento de los bosques y cubre un arco temporal de unos cuarenta años, de 1748 a 1789 . Antes de la primera fecha los cerramientos de fincas estaban permitidos y se realizaban libremente pero, tras la Ordenanza de Montes de 1748, se estipulaba en su capítulo 20 la prohibición a vecinos y comunidades de «apropiarse» de tierras no labradas bajo pena de 10 ducados por fanega cercada ${ }^{18}$. La ley, dirigida a salvaguardar las masas forestales, mencionaba las tierras de montes y baldíos pero no las fincas de labor ni la propiedad privada, aunque su espíritu sí las comprendía como se demuestra por el hecho de que la sucesiva ley de permiso general de cerramientos se remitía explícitamente a la medida tomada en 1748. Ya su mismo encabezamiento hablaba de «dueños particulares de tierras y arrendatarios», de «olivares o viñas con arbolado, o huertas de hortaliza con árboles frutales» ${ }^{19}$. Su objeto era, como cuarenta años antes, el de fomentar bien las vides bien los frutales, es decir que intentaba promocionar un tipo de explotación agraria que integrara sembradura y plantas y masas arbóreas. La novedad sustancial de lo establecido en 1788 era que se sancio-

17 Delgado, Jacinto María, Adiciones a la Historia del Ingenioso Hidalgo don Quijote de la Mancha, Madrid, Blas Román, s.a. [1784-1785] pp. 227 - 231. GUERRERO, 1988.

18 Real Ordenanza para el aumento y conservación de montes y plantios, 7/XII/1748. Novísima Recopilación, Libro VII, Título XXIV, Ley 14.

$19 R C$ 15/VI/1788 En que por punto y regla general se concede a los dueños particulares de tierras y arrendatarios, la facultad de que puedan cerrarlas o cercarlas, para hacer plantíos de olivares o viñas con arbolado, o huertas de hortaliza con árboles frutales: con lo demás que se expresa. Novísima Recopilación, Lib. II, Tit. XXIV, ley 19. 
naba que el agente principal del progreso económico era la propiedad privada, elevada por lo tanto al papel de interlocutor privilegiado en la política económica del Gobierno.

La real cédula de 1788 corregía algunas medidas anteriores a propósito de los nuevos plantíos, constatando que el período de prohibición de pastar para los ganados «en aquellos terrenos en donde se hiciesen nuevos plantíos y siembra de árboles en los primeros seis años que se consideraban precisos para su cría» se había demostrado demasiado breve y había hecho que muchos desistieran del empeño, lo que se veía como un fracaso de los deseos del gobierno. La solución lógica hubiera sido la concesión de permiso general de cercar cualquier heredad «nuevamente plantada», pero además de las disposiciones de 1748 había que tener en cuenta también los intereses de los ganaderos y su oposición a la política de cerramientos. El Consejo había presentado una consulta al rey el 23 de abril y la contestación había sido que se ampliara a propietarios o arrendatarios la facultad de cercar «los terrenos que se destinen para la cría de árboles silvestres, [...] veinte años que se consideran necesarios para el arraigo y cría de estos árboles, el cual cumplido, puedan entrar los ganados a pastar las yerbas de su suelo».

Hasta aquí en el fondo sólo se desarrollaba el articulado anterior, ampliando de seis a veinte años el período de prohibición de pasto en los terrenos plantados de árboles; pero el artículo II sancionaba una posibilidad nueva, la de los cultivos mixtos, en los que fincas de:

olivares o viñas con arbolado, o huertas de hortaliza con árboles frutales, deberán permanecer cerradas perpetuamente por todo el tiempo que sus dueños, o arrendatarios las mantengan pobladas de olivar, de viñas con arbolado, de árboles frutales, o de huertas con hortaliza y otras legumbres, para que de esta suerte conserven los terrenos su amenidad, y abunden en el reino estos preciosos frutos tan necesarios a la vida humana, y que contribuyen al regalo y al sustento de mis vasallos.

El artículo III concedía a los propietarios de las tierras el pleno derecho de «cercar las posesiones o terrenos que le conviniere en los términos que van expresados, sin la necesidad de solicitar concesiones especiales, como se ha hecho hasta aquí» ${ }^{20}$.

20 Seguía: Cap. IV.- «Ordeno a los Tribunales y Justicias del Reyno favorezcan estas empresas sin embargo de qualquier uso o costumbre en contrario, que no debe prevalecer al beneficio común, y al derecho que los particulares tienen para dar a sus terrenos el aprovechamiento y beneficios que le sean más lucrosos, y sólo en el caso de abandonar el cuidado de los plantíos, y el cultivo de sus huertas y cercados, deberán de caer de esta gracia los dueños de tales terrenos, por cesar la causa impulsiva de su concesión: quedando el mi Consejo en el cuidado de tomar las providencias convenientes para que tengan efecto los plantíos y su conservación, y de que no se abuse con pretexto de ellos de la facultad de cerrar y cercar las tierras». 
Esta medida daba libertad a las actividades económicas y también a la intervención capitalista en el mundo rural peninsular. El análisis histórico ilustra también que, hacia finales del Dieciocho, las tensiones entre los labradores y los ganaderos se habían decantado ya o se estaban decidiendo ya definitivamente en favor de los primeros, por lo que el fomento de los cerramientos respondía también a la realidad de una dinámica económica distinta en la que el olivar y la vid eran cultivos muy prometedores como indican Pascual y Ruiz $^{21}$ aunque no eran ni la panacea para la baja productividad de la tierra en la España interior ni conocieron aumentos espectaculares en Andalucía 22 .

Al observar las razones esgrimidas para solicitar las licencias de cerramiento se nota el peso de las quejas por los daños causados por los ganados en las tierras recién plantadas o labradas, comunes en prácticamente todos los expedientes. En Fregenal, en 1722, «han comenzado a criarse algunos chaparros que no pueden llegar a perfección a causa de que los ganados los roen y destrozan». El colegio de jesuitas en 1731 se quejaba por dos «chaparrales que tiene abiertos en el término y jurisdicción de la villa de Cumbres de San Bartolomé y que por ser los pastos comunes no puede lograr el fruto de la bellota, ni el de las yerbas». Son quejas ${ }^{23}$ reiteradas con, en común, el hecho de que éstas, y las de muchas otras, se fechan en los primeros cuarenta años del siglo XVIII; en los expedientes siguientes parecería como si los interesados no necesitaran ya especificar los inconvenientes de los ganados para justificar sus pretensiones.

Los expedientes de la Cámara son esclarecedores porque incluyen las peticiones y también las decisiones, ambas razonadas, como en los casos de Medina Sidonia, donde don Gaspar José Ximénez de Zurita y Larrea deseaba cerrar dos cortijos en 1775 y para ello se requería el informe de las autoridades locales, quienes certificaban que se trataba de tierras «sin tener en ellas participación, ni aprovechamiento común la Ciudad, Comunidad ni otra persona alguna», «mediante que se halla vacío sin arrendador, y acotado lo tendrá». Hasta aquí sólo se seguía la praxis habitual en tales casos, pero después venían algunas consideraciones de política agraria:

Confinando cualquiera dehesa cerrada con tierras baldías tiene más riesgo sus pastos, como más apetecidos por los ganados que disfrutan las baldías; y porque si las dehesas generalmente se hallaran cercadas de tierras cerradas, estuvieran más

21 PASCUAL y SUDRIÁ, 2002. Por la real provisión de 26/V/1770 se facilitaban los cerramientos tras el desarrollo de la norma con la real provisión de 28/IV/1793 y la real cédula de 24/V/1793. Sin embargo hubo pocos interesados a causa de la falta de medios para emprender los trabajos de «rompimiento» de las tierras y los principales beneficiarios fueron los labradores acomodados. RUIZ RODRÍGUEZ, 2004.

22 SEBASTIÁN AMARILLA, 2004: 152; GÁMEZ AMIÁN, 1989: 82-83.

23 Respectivamente en AHN, Consejos legajos 484/65 y 4492/18. 
guardadas de los Ganados que se les prohíbe, y muy fácil su custodia, al contrario que con las tierras abiertas, cuya guarda es muy trabajosa ${ }^{24}$.

Las consideraciones de don Manuel de Laguna y Moscoso, propietario en Badajoz, eran parecidas pero más articuladas:

No perdiendo de vista al mismo tiempo el promover la agricultura, aun conociendo la cuasi insuperable dificultad, dio principio a este proyecto desde el año de 1755, y no obstante de haber experimentado en la práctica aun mayores inconvenientes de los que había visto en sus ideas teóricas, ha proseguido en él hasta el día de hoy, y se lisonjea de tener descuajada una gran porción de dicho terreno, y haber hecho útil con trabajo y constancia una posesión que era un Bosque inhabitable, y muy poco hollado de gentes, y ganado.

Como buen amo, había levantado una casa cortijo para sus trabajadores, pero tenía que enfrentarse con los acostumbrados problemas de los ganados al pasto, con lo que formulaba su diagnóstico de la actividad agrícola:

Que confiesa que la concesión de grandes adehesamientos para numerosas Cabañas sin labor es perjudicial al Común y al Estado, e impeditiva de la población, y sirve sólo para enriquecer unos pocos que estancando las lanas, y Carnes logran una vida sin afanes con penuria de todos los demás, y por el contrario una labor grande o mediana sin ganados para fomentarla sólo sirve de perder al labrador con ninguna utilidad del Estado: y unas labores medianas con ganados correspondientes son útiles a los mismos labradores y al Estado, sirven de amenidad a los campos, y abundan los Pueblos.

Ante su petición la ciudad de Badajoz proponía que se limitara la licencia de cerramiento mas «que esto se haya de entender por solo el tiempo que labrare, pues en otro caso quedará de aprovechamiento común», y la Cámara la concedía a condición de que siguiera con los plantíos otros ocho años más, y de que prefiriera a los vecinos del mismo pueblo en caso de arrendar la finca una vez cercada. Tenía que satisfacer un "servicio» - precio habitual de las gracias otorgadas- de ducado por fanega ${ }^{25}$. Cabría pensar que en algunos casos las peticiones de cerramiento representaran la manifestación del conflicto entre ganaderos y agricultores, como ocurrió también en Bornos a Francisco Alonso González de Ballesteros, dueño de una tierra llamada Güertos de Zerrezín, comprada en 54.483 reales y 12 maravedíes, de 200 fanegas (1.288 ha) de sembradura y «más de dos mil olivares en el término de dicha villa». La había adquirido en 1787 después de haberla llevado en arrendamiento durante varios años, pero resultaba que el ganado de dos dehesas contiguas le había

24 AHN Consejos, legajo 4577/164, de 20/II/1775.

25 AHN Consejos, legajo 4604/86, de 18/VIII/1787. 
comido «novecientas estacas de olivo»: en 1789 exponía al Consejo que en sus tierras «no me atrevo a continuar dicho plantío sin que proceda cerrar, cercar y vallar mi referida hacienda», es decir que deseaba hacer valer sus derechos de propiedad para poder continuar su inversión productiva. Chocaba con los intereses de los demás vecinos, amparados por la costumbre de «que los olivares del término de esta villa sólo desde el día del Sr. San Miguel de cada año son cerrados hasta alzado el fruto pendiente», como se defendía la villa. El asunto llegó al Consejo y la decisión fue que los posibles perjudicados presentaran sus alegaciones individualmente, sin atender a los derechos del pueblo ${ }^{26}$; de hecho se ponía de la parte del propietario contra la costumbre «bárbara» del uso de los comunales. Por otra parte el papel del ganado en las disputas por los cerramientos es muy interesante, porque en algunos casos quienes pretendían cerrar intentaban defenderse de las incursiones de los animales ajenos, pero en otros lo que se deseaba era impedir que el ganado propio saliera de la propiedad y abonara las tierras de los vecinos. Se encuentra un eco de este problema no solamente en las peticiones ya mencionadas, sino también en algunas declaraciones del Catastro de Ensenada, como en Zafra, donde las tierras de labor producían de 6 a 8 fanegas de trigo por fanega superficial si estaban cercadas, y de 3 a 5 en hoja: «La razón de producir los cercados más la ocasiona el beneficio del estiércol» ${ }^{27}$. Así que el aspecto de protección de las fincas ante las incursiones de animales ajenos no era siempre la razón de un cerramiento y desde luego dependía del cultivo en la finca cerrada.

Hacia el último cuarto del siglo se constataba, como justificación, lo que era un movimiento general. Un propietario de varios fondos en La Adrada, incluidos en la dehesa de la Avellaneda,

donde es grande la abundancia de ganados mayores, y menores que hay pastando sus yerbas; por cuyo motivo no puede sembrar, ni plantar especie de árbol fructífero sin cerrarla de tapia o pared de piedra según los están las demás heredades situadas en dicha villa,

se hacía fuerte en sus pretensiones por el hecho de que otros habían realizado cerramientos «sin oposición alguna, [...] sin las circunstancias de haberse hecho plantío, y sin más licencia que decir quiero cerrar, y consentirse por los Capitulares». Lo más llamativo es que al oír semejantes razones la Cámara quedaba satisfecha y concedía la gracia solicitada en $1776^{28}$.

26 AHN, Consejos, legajo 1284/6, de 24/XII/1789.

27 Zafra, 1753. El Catastro de Ensenada está disponible en pares.mcu

28 «Sirviendo» con 1,5 ducados/fs. AHN, Consejos, legajo 4579/121, de 29/VII/1776. 


\section{VÍAS DE ADQUISICIÓN}

Como estipulaban las leyes y se manifiesta en los expedientes, para conseguir la licencia de cerramiento había que convocar a los vecinos del lugar y asegurarse por sus declaraciones de que la actuación no habría causado perjuicio alguno «a la villa y vecinos». Las condiciones también reguladas por las leyes eran: el visto bueno de los demás vecinos, que hubiera tierra libre suficiente para el pasto de los ganados del pueblo, que las tierras cercadas fueran propiedad del interesado o las tuviera en arrendamiento, y «no haber por ellas paso de ganados, ni cañada real de Mesta».

Los ejemplos arriba reunidos muestran que esas condiciones no siempre se respetaban y que eran los poderes públicos los primeros en no respetarlas. El acatamiento del bien común se hace patente en las declaraciones de algunos solicitantes, como don Manuel de Laguna y Moscoso, de Badajoz, «Que no se atreve a pedir esta gracia si fueran las tierras del todo baldías, porque sería querer adquirirlas con perjuicio de otros». Sin embargo a finales del siglo la situación general era completamente contraria a los campesinos menos favorecidos, como aparece de las continuas quejas de abusos cometidos por los pudientes. En Villanueva del Fresno, en 1789, los vecinos denunciaban las irregularidades en el gobierno local y las usurpaciones «de los aprovechamientos comunes que con grave perjuicio de aquel pueblo se hacen por la Marquesa de Villena y por la familia de los Quevedos» a la vez que proponían una providencia que al llegar a Madrid Floridablanca pasaba a Campomanes y de la que no queda más rastro documental ${ }^{29}$. En el mismo año en Lillo se oían protestas por la «opresión que sufren de parte de los poderosos, particularmente en el despojo de las tierras baldías y concejiles que les estaban repartidas para su labranza y aprovechamiento por providencia del mismo Consejo ${ }^{30}$, ejemplos que no son excepcionales sino que reflejan la dinámica de los asuntos en materia de cerramientos durante todo el siglo.

En los primeros años del Setecientos en las Canarias unos vecinos habían descuajado ciertas tierras en el Pago de la Sardina, «baldías y realengas», sin título para ello. Tras varias sentencias de 1702 y 1703 la justicia había decidido que los culpables regularizaran su situación pagando medio ducado por fanega usurpada, mas como los interesados no habían querido valerse de ese medio de adquirir la propiedad, en 1716 Don Francisco Amoreto Manrique solicitaba que de esas tierras se le concedieran 609 fanegas en consideración a sus méritos al servicio de la Corona, y no a título de gracia, sino pagando 2.500 escudos de plata. En este proceso primero hubo una usurpación de bienes comunales, después una propuesta de las autoridades para subsanarla me-

29 Decretos de Gracia, AHN, Consejos libro 830/99v.

30 22/V/1789, AHN, Consejos libro 830/152. 
diante una compra, y por último la intervención de una tercera parte que se ofrecía a adquirir dichas tierras. Lo que marca todo el asunto es la irregularidad inicial, por lo que la propuesta de Amoreto no era una transacción usual de compraventa sino que se debía justificar por los méritos especiales del demandante. Al final el resultado era el mismo que en tantos otros casos, un cerramiento y un terreno sustraído al aprovechamiento común al que había sido destinado en su origen ${ }^{31}$.

En 1681, el ayuntamiento de Martos había pasado por dificultades financieras y un vecino se había ofrecido a anticipar dinero tomando como garantía la dehesa Cazalla, pero no un vecino cualquiera, sino uno de los regidores, y, según las fuentes, el más rico y poderoso. En 1720 el municipio impugnaba aquella venta encubierta de un bien comunal pero la Cámara se inclinaba por mantener los derechos del comprador y sus descendientes ${ }^{32}$. En cambio las deudas de la Corona no siempre se reconocían suficiente motivo para conseguir ese tipo de premio: el teniente capitán don Juan de Ocejo pretendía que por sus servicios prestados se le permitiera cerrar 60 fanegas «en sembradura en los montes realengos de la Fraga de Santiago de Boado, jurisdicción de Mesía, donde es oriundo». El informe de la Audiencia de Galicia decía que el valor de esas tierras era muy bajo, a lo sumo de 8 reales por fanega, y la licencia no habría perjudicado a nadie; pero la Cámara ni encontraba que el mérito estuviera justificado «ni los sueldos vencidos que supone» y rechazaba la petición en 1727. Ocejo volvía a intentarlo con los mismos argumentos diez años más tarde y se le denegaba como diez años antes ${ }^{33}$.

La documentación permite por lo tanto ver que, si en algunos momentos se había legislado para regular el fenómeno de los cerramientos, éstos se trataban a menudo como gracias otorgadas por la Cámara de Castilla obviando así toda la legislación. Entonces habrá que analizar la relación necesidad/práctica de racionalización de las actividades económicas y la intervención gubernativa entendida como dirección política o mera muestra de generosidad del poder ante los interesados.

En lo que se refiere al régimen de propiedad de las fincas que se querían cerrar, pocos son los casos en que las tierras eran de nueva adquisición, lo que indica de paso que los movimientos de propiedad de la tierra aún eran poco pronunciados debido a la escasez de tierra disponible en el mercado. Generalmente se trataba de fincas que desde hacía mucho pertenecían a los solicitantes, pero las peticiones de quienes recientemente habían adquirido tierras a título oneroso precisamente para acotarlas y cerrarlas indican un interés explícito en las inversiones agrarias, como resulta evidente en varios casos. Don

31 Parecer favorable de la Cámara de 22/VI/1718, AHN, Consejos, legajo 4481/30.

32 AHN, Consejos legajo 4482/61, de 16/XII/1720.

33 AHN, Consejos legajo 4487/64 y 4498/101. 
Santiago de Arostívar y Villa, de Pastrana, había comprado una finca en 2.500 reales cuando estaba en erial a los antepasados del último vendedor, «en cuyo poder ha venido a menos, a causa de las continuas entradas de los ganados que destruyen los plantíos». En otros tiempos había estado cerrada «como lo demostraban las ruinas de las tapias que en lo antiguo había tenido», tan antiguo como casi siglo y medio atrás. Ahora, en 1742, deseaba «restablecer» su finca plantando olivos pero para eso era imprescindible cerrarla. Igual de emprendedor había sido don Rafael Luminati y Camargo de Motril en 1745, quien había adquirido 615 fanegas (376,45 ha) en el Barranco del Vaquero, de las cuales 50 de sembradura y el resto de monte bajo para cultivarlas; naturalmente pretendía poder cerrarlas para lograrlo. Hay que pensar que también la operación que realizó don Diego de Soria en Morón de la Frontera en 1775 respondería a criterios de racionalidad económica porque para esa fecha había invertido ya 107.140 reales en 318 fanegas $(189,04 \mathrm{ha})$ de tierra de varia calidad, toda de monte, y dos años más tarde solicitaba licencia para cerrarlas y «lograr un chaparral fructífero». En 1787 Francisco Alonso González de Ballesteros compraba 200 fanegas de tierra y «más de dos mil olivares» que «antes la tenía en arrendamiento» en 54.483 reales y 12 maravedíes, y a los dos años pretendía hacer cerramiento.

Se pueden contar siete expedientes de petición de cerramiento de tierras comunales que se concedieron a quienes los solicitaban; otros dos interesan la venta de bienes comunales y sólo un caso, el de Miguel Topete de Morón en 1720 se refiere a un arrendatario de 789 fanegas $(469,04 \mathrm{ha})$ de sembradura y pasto. Se puede decir que la práctica de concesión de bienes comunales sólo es una de las facetas del movimiento de cerramientos del siglo XVIII. En lo que se refiere a la superficie de los bienes comunales pasados a manos privadas, se va de un cuarto de fanega a 1.020, con una extensión media de 207,14 fanegas por cerramiento ${ }^{34}$.

\section{BENEFICIOS ESPERADOS}

Del conjunto de los expedientes también se puede conseguir información sobre el beneficio de las inversiones en el campo todas las veces en que se mencionan los valores de las tierras interesadas en los cerramientos y las rentas que producían y que iban a producir una vez cerradas ${ }^{35}$. De la tabla 3 se

34 Dada la localización de la gran mayoría de los predios, se puede tomar como indicativa la fanega de Sevilla, de cerca de $6.000 \mathrm{~m}^{2}$.

35 Difícil calcular la productividad agraria: véanse GARCÍA SANZ y SANZ FERNÁNDEZ, 1988; BERNAL, 1988; GÁMEZ AMIÁN, 1989; LLOPIS AGELÁN, 2002; SEBASTIÁN AMARILLA, 2004. Los datos de la serie de Consultas de Gracia son muy limitados, y 
deduce que la cuantía corriente de la renta agrícola era el 3\% del valor de la finca, pero este dato sólo está especificado en 12 expedientes. Lo que es significativo de esa docena de casos es que en cinco era superior, y en dos de los tres ejemplos en que la renta superaba el $4 \%$ el cultivo que la producía era de olivar y vides.

TABLA 3. Valores indicativos de la tierra según su cultivo, en reales/fanega, renta actual y renta prevista tras el cerramiento, en porcentaje sobre el valor de la tierra, según las peticiones de gracia.

\begin{tabular}{|c|c|c|c|c|c|c|}
\hline AÑO & LUGAR & CULTIVO PROYECTADO & FS. & VALOR & RENTA & PREVISTO \\
\hline 1730 & Jaén & Olivar y vides & 188 & $6.180,13$ & 4,01 & \\
\hline 1741 & Tordesillas & Prado tierra pan llevar & 50 & 240,00 & 3,16 & \\
\hline 1763 & $\begin{array}{l}\text { Sanlúcar } \\
\text { Barrameda }\end{array}$ & Sembradura & 240 & 440,00 & 4,54 & 4,77 \\
\hline 1769 & Ronda & Sembradura & 144 & 77,00 & Especie & \\
\hline 1770 & Ronda & Monte & 350 & 00,00 & 0 & $15,71 \mathrm{rs}$ \\
\hline 1773 & $\begin{array}{l}\text { Medina } \\
\text { Sidonia }\end{array}$ & Monte & & 50,00 & & \\
\hline 1773 & $\begin{array}{l}\text { Medina } \\
\text { Sidonia }\end{array}$ & Cortijo, sembradura & 164 & 100,00 & Especie & 40 fs. pan \\
\hline 1773 & $\begin{array}{l}\text { Medina } \\
\text { Sidonia }\end{array}$ & Cortijo, sembradura & 228 & 187,00 & 3,20 & \\
\hline 1774 & $\begin{array}{l}\text { Medina } \\
\text { Sidonia }\end{array}$ & Cortijo, labradío & 115 & 220,00 & 2,72 & 3,18 \\
\hline 1776 & La Adrada & Sembradura, centeno & 19 & 29,40 & Especie & \\
\hline 1776 & La Adrada & Sembradura & 5 & 44,00 & Especie & \\
\hline 1776 & La Adrada & Sembradura & 7 & 50,00 & Especie & \\
\hline 1777 & $\begin{array}{l}\text { Morón de la } \\
\text { Frontera }\end{array}$ & Monte & 118 & 230,00 & & \\
\hline 1777 & $\begin{array}{l}\text { Morón de la } \\
\text { Frontera }\end{array}$ & Monte & 200 & 400,00 & & \\
\hline 1780 & Burguillos & Olivar, pésima calidad & 10 & 440,00 & 1,02 & 2,27 \\
\hline
\end{tabular}

los resultados puramente indicativos. En algunos casos se comparan en este estudio con lo declarado en el Catastro de Ensenada. Sobre los precios de la tierra, GONZÁLEZ BELTRÁN, 2004: 311-322. 


\begin{tabular}{|l|l|l|r|r|r|r|}
\hline AÑO & \multicolumn{1}{|c|}{ LUGAR } & CULTIVO PROYECTADO & \multicolumn{1}{|c|}{ Fs. } & VALOR & RENTA & PREVISTO \\
\hline 1782 & $\begin{array}{l}\text { Dos Her- } \\
\text { manas }\end{array}$ & Sembradura & 77 & $2.066,00$ & 1,57 & 3,00 \\
\hline 1784 & Zafra & Sembradura & 1.038 & 52,98 & 0,00 & 3,00 \\
\hline 1784 & Sevilla & Olivar & 600 & $1.800,00$ & 2,50 & \\
\hline 1787 & Estepa & Cortijo con casa, pozo & 701 & & 2,95 & \\
\hline 1787 & Estepa & Garrotal [olivar] nuevo & 413 & $1.600,00$ & 3,00 & \\
\hline 1788 & $\begin{array}{l}\text { Villalba de } \\
\text { Alcor }\end{array}$ & Olivar y vides & 79 & $1.127,16$ & 4,32 & \\
\hline 1789 & $\begin{array}{l}\text { Usagre } \\
\text { (Llerena) }\end{array}$ & Sembradura & 414 & 132,85 & Especie & \\
\hline
\end{tabular}

A excepción de una finca de 10 fanegas de «pésima calidad», cuyo valor unitario era de 440 reales, se comprobará que los precios más elevados eran los de las tierras de olivares y viñedos, todos por encima de 1.000 reales/ fanega, con la punta máxima en Jaén de 188 fanegas valoradas en 6.180,13 reales cada una. Mientras que la mayor parte de las tierras más caras se encontraban en Sevilla, las rentas más elevadas correspondían a explotaciones de fincas diseminadas por varias provincias y dedicadas a varios tipos de producción: el olivar arrojaba rentabilidades de 4,01 y 4,32 por ciento, superiores al 3,20\% medio de las tierras de sembradura, mas parece que la finca de Sanlúcar ha sido la más rentable con un producto anual del 4,54\% de su valor, que subiría hasta el $4,77 \%$ previsto una vez cerradas sus tierras de sembradura. Los encinares también, como se declaraba para la Única Contribución: «Cada fanega de tierra poblada de encinas de particulares produce $30 \mathrm{rs}$. de vellón si fuera acotada, y las que no veinte y cuatro» ${ }^{36}$ es decir un $25 \%$ más. Sea como fuere las rentas, unidas a la revalorización una vez realizados los cerramientos, volvían las fincas interesantes para las intervenciones capitalistas porque los beneficios eran superiores a lo que ofrecían las formas tradicionales de inversión, juros o censos urbanos.

En lo que afecta a los aspectos puramente agrícolas de la explotación y transformación de los usos de la tierra, por la tabla 3 se puede observar también la gran variedad de fincas interesadas y su distinta calidad. El mismo propietario de La Adrada poseía tierras de sembradura valoradas en 50 y casi 30 reales/fanega en cada finca -con una diferencia de valor del 40\%- y otras labradas a centeno que valían menos de la mitad, 19 reales por fanega.

36 Cumbres de San Bartolomé, 1751, en Catastro de Ensenada, disponible en pares.mcu 
Parecidas diferencias también se observan en las tierras de monte, donde una fanega podía valer 50 reales en Medina Sidonia y 400 reales en Morón; una fanega de olivar tenía un abanico de valores aún más amplio, pues podía ir de 440 reales a más de seis mil. Además se debe notar que las tierras de olivar, aunque fueran de muy baja calidad, tenían un valor más elevado que el de muchas fanegas de buena tierra de sembradura, lo que indica que se trataba de una forma de cultivo muy rentable y deseada.

TABLA 4. Valores de adquisición de la tierra según su uso

\begin{tabular}{|l|c|c|c|}
\hline USO & SUP. FANEGAS & VALOR RS. & VALOR RS./FS. \\
\hline Monte & 731 & $767.940,00$ & $1.050,53$ \\
\hline Olivar y vid & 877 & $317.630,08$ & 362,17 \\
\hline Sembradura & 2.501 & $483.227,74$ & 193,21 \\
\hline
\end{tabular}

En cambio, si se toman en consideración los precios de las tierras en su conjunto, como en la tabla 4 , siempre con la salvedad del limitado número de casos especificados, se verá que las fincas más buscadas eran las de monte seguidas de los olivares y por último las tierras de sembradura, según un diferencial bien acusado: el valor medio de una fanega de monte era respectivamente tres y casi ocho veces superior al de una de olivar o de sembradura. Claro que estos datos se deben tomar cum grano salis a causa de la exigüidad de la muestra.

En las contestaciones a la Única Contribución de los pueblos implicados en las peticiones de gracia se refleja esa diferencia de rentabilidad de los cultivos; la tabla 5 indica el producto anual en reales de una superficie equivalente de huerto, vid y olivar comparado con el de una fanega de trigo en los lugares en que se solicitaron las licencias de cerramiento.

Está claro que además de los huertos, que rendían decenas de veces más por la misma superficie cultivada, el vino y el aceite eran muy atractivos en cuanto a rentabilidad y así se puede explicar la demanda de tierras de monte para su descuaje y cultivo, o para actividades ganaderas a gran escala, puesto que no se concibe la posibilidad de sustituir trigo por olivar o vid. Es decir, que el valor de la tierra estaba determinado por su posible uso futuro más que por la rentabilidad presente de lo que en ella se cultivaba. Esto es una señal inequívoca de una actividad económica dinámicamente orientada. 
TABLA 5. Producto de varios cultivos, por fanega. Trigo $=100$. Según Catastro de Ensenada.

\begin{tabular}{|c|c|c|c|c|}
\hline LUGAR & HUERTO & CEBADA & VINO & ACEITE \\
\hline Alconchel & & 50,00 & & \\
\hline Antequera & $1.545,00-2.804,55$ & 40,90 & $454,55-1.136,36$ & $190,90-318,81$ \\
\hline Ayamonte & $4.400,00$ & 48,00 & $720,00-2.160,00$ & \\
\hline Badajoz & & 50,00 & & 600,00 \\
\hline Baena & & 50,00 & $333,33-888,88$ & $166,66-12.000$ \\
\hline Bornos & $8.343,07$ & 66,66 & & $250,00-666.66$ \\
\hline Burguillos & $8.000,00$ & 50,00 & & $465,00-775,00$ \\
\hline $\begin{array}{l}\text { Cabezas de San } \\
\text { Juan }\end{array}$ & $1.066,66$ & 66,66 & 600,00 & \\
\hline Carmona & $2.062,50-2.750,00$ & 56,25 & $125,00-312,50$ & \\
\hline Castro del Río & $2.500,00$ & 50,00 & & \\
\hline Chiclana & & 53,33 & $283,33-906,60$ & $2.666-4.666$ \\
\hline Cuenca & $944,44-2.222,22$ & 50,50 & & \\
\hline $\begin{array}{l}\text { Cumbres S. Barto- } \\
\text { lomé }\end{array}$ & $5.500,00$ & 40,00 & $1.400,00$ & $1.800,00$ \\
\hline Écija & $2.666,66-8.000,00$ & 66,66 & & \\
\hline Estepa & & 50,00 & & \\
\hline Fregenal & $5.000,00$ & 44,44 & $1.000,00$ & $1.888,88$ \\
\hline Guádix & $1.833,33$ & 50,00 & & \\
\hline Jaén & & 50,00 & & \\
\hline $\begin{array}{l}\text { Jerez de los Caballe- } \\
\text { ros }\end{array}$ & $1.466,66-2.200,00$ & 50,00 & $800,00-1.600,00$ & $400,00-800,00$ \\
\hline Jerez de la Frontera & $1.975,00$ & 50,00 & & \\
\hline La Adrada & $1.250,00$ & 53,12 & $40,00-75,00$ & \\
\hline La Campana & $2.250,00$ & 66,66 & & \\
\hline La Rinconada & $7.058,82$ & 47,06 & & 582,35 \\
\hline Lebrija & & 62,50 & $250,00-750,00$ & \\
\hline Llerena & $7.333,33$ & 53,33 & $1.333,33$ & $640,00-1.706,66$ \\
\hline Medina Sidonia & $4.611,10-13.972,20$ & 44,44 & & \\
\hline Morón & & 55,55 & & \\
\hline Motril & & 40,00 & 75,00 & $3.600,00$ \\
\hline Osuna & 484,92 & 79,36 & & \\
\hline Pastrana & $2.647,05-3.235,29$ & 47,05 & $176,47-470,58$ & $107,88-423,50$ \\
\hline Puerto Santa María & $7.500,00-11.000,00$ & 60,00 & $600,00-2.100,00$ & $300,00-600,00$ \\
\hline Ronda & & 50,00 & & \\
\hline Sanlúcar Barrameda & $3.280,04$ & 50,45 & $545,45-1.636,36$ & \\
\hline Santaella & $4.000,00$ & 53,33 & & $400,00-800,00$ \\
\hline
\end{tabular}




\begin{tabular}{|l|c|c|c|c|}
\hline LUGAR & HUERTO & CEBADA & VINO & ACEITE \\
\hline Tordesillas & & 41,66 & $300,00-1.000,00$ & \\
\hline Usagre & $666,66-1.333,33$ & 46,66 & & $533,33-1.066,66$ \\
\hline Valencia Alcántara & & 46,66 & $186,66-560,00$ & $300,00-700,00$ \\
\hline Vera & $1.920,00$ & 38,88 & $448,00-960,00$ & \\
\hline Villalba del Alcor & & 44,44 & & \\
\hline Villalpando & 363,63 & 66,66 & & \\
\hline Villanueva del Río & & 50,00 & & $714,00-1.785,00$ \\
\hline Zafra & & 50,00 & $225,00-1.462,50$ & $450,00-1.350,00$ \\
\hline
\end{tabular}

\section{DIMENSIONES DE LOS CERRAMIENTOS}

Analizando los datos de los expedientes también cabe hacer algunas consideraciones cuantitativas sobre los 69 casos registrados. La superficie total de tierras objeto de esos cerramientos es de 20.921,7 fanegas, y la extensión media de cada finca es de 332,09 fanegas.

Para poder hacer una comparación puramente ilustrativa, se han clasificado en la tabla 6 las peticiones de gracia según las superficies de las fincas y los intervalos que da Cruz Villalón en su estudio sobre Carmona ${ }^{37}$. Admitiendo que la situación en esa ciudad represente una cierta «norma» en la realidad rural, entonces las intervenciones de cerramiento realizadas en el siglo XVIII se encuentran en cierto sentido fuera de esa «norma», puesto que los indicadores de las superficies acotadas se desplazan hacia los valores más altos. Esto significa que la práctica de los cerramientos no era patrimonio del mundo campesino en su conjunto sino asunto reservado a una cierta capa de propietarios en busca de más beneficios para sus posesiones, generalmente algo mayores que la media pero en cualquier caso muy lejos de lo que eran las superficies usuales de los latifundios andaluces en el siglo XVIII, cuyos valores medios, máximos y mínimos eran respectivamente $751,1.610$ y 451 fanegas $^{38}$.

TABLA 6. Distribución de la propiedad en Carmona y según los expedientes de Gracia. Porcentaje de casos según la superficie en fanegas.

\begin{tabular}{|l|c|c|c|c|c|}
\hline & $<4$ & $4-40$ & $41-400$ & $401-4.000$ & $>4.000$ \\
\hline Carmona & 24,44 & 53,65 & 16,23 & 5,32 & 0,36 \\
\hline Cerramientos vía Gracia & 4,61 & 15,38 & 53,84 & 24,61 & 1,53 \\
\hline
\end{tabular}

37 CRUZ VILLALÓN, 1980. PÉREZ PICAZO, 1998. LARA RAMOS, 1999.

38 BERNAL, 1988: 125 
Elaborando los datos de 1752 para Andalucía, Gámez Amián ha establecido que las heredades de menos de 5 ha eran siempre más de la mitad el conjunto menos en Montefrío y precisamente en Carmona también. Las fincas de entre cinco y cincuenta ha de superficie representaban entre el $20 \%$ y el $25 \%$ del total; menos en Cabra los cortijos de entre 50 y 100 ha son el $6 \%$ o menos del total y sólo en Montefrío los cortijos de entre 100 y 500 ha superaban el $10 \%$ de los casos, y en toda Andalucía las propiedades de más de 500 ha eran puramente casos testimoniales menos en Palma del Río donde representaban el $8 \%$ de los $\operatorname{casos}^{39}$. Convendrá recordar que a los ojos de los contemporáneos un cortijo de 2.000 fanegas sevillanas, es decir de unas 1.200 hectáreas, no se consideraba grande, según Olavide ${ }^{40}$.

Pero en valores absolutos sólo la tercera parte de los cerramientos afectaban a una superficie igual o mayor de 350 fanegas, es decir que estaban por encima del valor medio de superficie de las heredades.

\section{Distribución geográfica}

Se hace evidente la presencia de cerramientos sobre todo en Andalucía y especialmente en la Occidental según la tabla 7; sólo las dos provincias de Cádiz y Sevilla juntas arrojan casi la mitad de los casos documentados y también $8.576,8$ fanegas cerradas, o el 40,99\% de la tierra afectada. En Andalucía ocurrieron 54 de los 69 casos, e interesaban al 80,85\% de lo acotado. La sola provincia de Sevilla recoge la tercera parte de los cerramientos en el siglo XVIII.

Andalucía significa especialmente el área de influencia de Sevilla: Medina Sidonia, Jerez de la Frontera, Cumbres de San Bartolomé, Osuna, Morón (2 casos), La Rinconada, Carmona y la misma Sevilla. Esto demuestra también que los movimientos de racionalización capitalista en el ámbito agrario, por limitados que fueran, ocurrían en zonas geográficas concretas o, lo que es lo mismo, que no se trataba de un movimiento generalizado. Para 19 de esas mismas fincas que se pretendía cerrar y acotar se puede establecer el uso que se les iba a dar, y así se encuentra que la gran propiedad de Jerónimo Ruiz en Jaén, de 5.000 fanegas $(3.131,4$ ha), podía dedicarse a sembradura, bellota y olivo, exactamente igual que otra diez veces más pequeña en Antequera; solamente dos heredades, de 376 y 600 fanegas (223,52 y 356,66 ha) respectivamente, en Medina Sidonia y Morón, se cerraban para hacer sólo sembradura. A solo pasto se pondrían dos cerramientos, uno en Vera, de 615 fanegas (396 ha), y el otro en Badajoz, de 1.000 fanegas (6439 ha) de superficie, y

39 Claro abanico latifundio-minifundio. La autora hace referencia a propiedades individuales, no a las superficies de conjunto en cada lugar. GÁMEZ AMIÁN, 1989: 89

40 Opinión citada por ANES, 1996: 96. 
curiosamente por los mismos años, 1725 y 1726. Para bellota y pasto, es decir, para dehesa, se reservaban ocho fincas de las 19 más grandes, pero la creación de este tipo de uso se ampliaba también con las 600 fanegas $(356,68$ ha) en La Rinconada o las 550 (326,95 ha) en Osuna de dehesa mixta con olivar, mientras que sólo una de los cerramientos más grandes, de 600 fanegas en Sevilla, se dedicaba exclusivamente a olivar. Otra forma mixta de explotación era la que se quería realizar en Espiel de Sierra Morena cuyas 2.000 fanegas acotadas se pondrían a olivar mixto con vid.

TABLA 7. Localización geográfica, superficie cerrada, porcentajes del total de cerramientos, y superficie media de cada caso, según las consultas de Gracia. (El valor medio total se ha calculado sobre 61 casos, únicos que ofrecen todos los datos necesarios).

\begin{tabular}{|l|r|c|c|c|}
\hline PROVINCIA ACTUAL & CASOS & HECTÁREAS CERRADAS & \% DEL TOTAL & $\begin{array}{c}\text { SUPERFICIE } \\
\text { MEDIA, HA }\end{array}$ \\
\hline BADAJOZ & 12 & $2.536,87$ & 19,64 & 211,41 \\
\hline ALMERÍA & 1 & 360,33 & 2,79 & \\
\hline CÓRDOBA & 7 & $1.709,04$ & 13,23 & 244,14 \\
\hline CÁDIZ & 12 & $1.157,83$ & 8,96 & 96,49 \\
\hline CUENCA & 1 & 2,90 & 0,02 & \\
\hline GRANADA & 3 & $1.284,70$ & 9,95 & 428,23 \\
\hline HUELVA & 2 & 0,92 & 0 & \\
\hline JAÉN & 2 & 744,01 & 5,76 & 372,0 \\
\hline MÁLAGA & 6 & $1.060,71$ & 8,21 & 176,79 \\
\hline SEVILLA & 21 & $4.033,12$ & 31,23 & 192,05 \\
\hline VALLADOLID & 2 & 25,04 & 0,19 & 12,52 \\
\hline \multicolumn{1}{r|}{ TOTAL } & 69 & $12.915,47$ & 99,98 & 187,18 \\
\hline
\end{tabular}

\section{Usos de los cerramientos}

En conjunto, 60 expedientes indican el fin que se iba a dar a la finca una vez acotada, y exceptuando las peticiones de licencia de Jerez de los Caballeros en 1738 para cerrar 100 fanegas de coto de caza y de Zafra en 1775 para hacer un coto de pesca en una charca, todas las peticiones se referían a intervenciones productivas, no recreativas. En Jerez también en 1757 se quería reservar un pequeño predio de 4,5 fanegas para construir una almazara, y en 1787 en Dos Hermanas se pedía licencia de cerrar 77 fanegas para un huerto. 
Ocurría a veces que la petición era tan detallada que se especificaba en ella todos los cultivos que se realizarían una vez autorizado el cerramiento. La hacienda de don Antonio Manso en Málaga, de 172 fanegas, se organizaría así: casi la mitad — 88 fanegas - a sembradura, y las demás se destinaban a «plantíos de vides, 1.875 olivos, 970 limones, 1.750 almendros, 199 higueras, 120 pies de «parrolos», 120 álamos, 24 granados, 5 algarrobos, 2 chaparrillos, 3 perales, 4 morales, 9 cipreses, 3 palmas, 21 membrillos, 3 ciruelos», combinando de esa manera la producción de cereal, aceite y fruta ${ }^{41}$.

Del examen de las peticiones de gracia también se reafirma que, entre la fecha de la primera — 1720 — y de la última - 1789—, el bien más apreciado era la dehesa, que aparece mencionada cinco veces fuera de Andalucía y 19 den-tro. Así se aprovechaban tierras «infructíferas», como rezaba la súplica de Fregenal. En Jaén el dueño de un cortijo de 5.000 fanegas quería cerrarlo para dedicarlo a «criar doce mil pies de olivos, huerta y encinar, en que se interesará la Real Hacienda con los frutos que puedan producir y en lo sucesivo hacer población, de que no se sigue perjuicio considerable» ${ }^{42}$.

En los cerramientos se ha abandonado la sembradura probablemente porque se trataba de tierras demasiado marginales para la labranza, pero de las que se habría podido obtener, como en Ronda,

un bosque muy bueno que produciría mucha madera y leña, y mucho fruto de bellota para los ganados de cerda, tan precisos para el abasto común a quien resultaría notorio beneficio, pues la abundancia de esta especie haría que valiese menos de lo que al presente vale y así con más abundancia se abastecerá no sólo aquel pueblo, sino también el de Cádiz, Puerto de Santa María, Jerez, Sevilla y otros ${ }^{43}$.

La superficie de las fincas que se quería adehesar variaba de 9 a 1.080 fanegas, casos de Valencia de Alcántara y Granada, respectivamente. La forma de explotación a dehesa, esto es terreno arbolado y mixto con pasto, se repartía el favor de los propietarios con los cerramientos para uso exclusivo de pasto, con cuatro expedientes en 1725 y uno en 1761, en Badajoz de 1.000 fanegas, en Cuenca de 4,5 fanegas, en Vera y en dos fincas de Córdoba. Luego en 29 casos de 60 el interés de quien intentaba acotar sus tierras apuntaba a favorecer el sustento del ganado.

Aquí aparece por lo tanto un hecho indiscutible pues se apoya en datos concretos como pueden ser los intereses manifestados por los mismos promotores de las peticiones y que contradice la visión teórica de los políticos reformadores que no consideraban la dehesa como la forma más adecuada para

41 AHN, Consejos legajo 4580/3, de 26/IV/1777.

42 Fregenal, AHN, Consejos, legajo 4490/57, 28/IX/1729; Jaén, 28/V/1742, leg. 4505/39.

43 AHN, Consejos, legajo 4561/39, de 3/III/1770. 
aumentar la productividad y la riqueza de las haciendas. Una posible, e importante conclusión que cabe sacar de esta discrepancia es que los propietarios que pedían licencia de cerramiento para hacer una dehesa no entendían aumentar la riqueza de la nación sino que buscaban asegurarse un beneficio seguro recurriendo a un uso agrícola tradicional pero de poco riesgo. De hecho tampoco los esfuerzos por mejorar los cultivos, que presuntamente deberían indicar una mentalidad innovadora, son abundantes y aparecen sólo en tres casos declarados para interesar 1.276 fanegas en Morón, Guádix y Medina Sidonia, lo que representa apenas el 5\% del total de la superficie de los cerramientos. Por si fuera poco, dos de las tres súplicas se remontan a principios de siglo, a 1719 y a 1732, lo que indica que se trataba de una intención no demasiado seguida en la práctica. Se podría pensar que el cultivo del olivar ofreciera una indicación segura del interés de los propietarios por nuevas formas de agricultura productiva, pero solamente 17 expedientes mencionan este uso como justificación para solicitar la licencia de cerramiento. Lo que sí es significativo es que diez de ellos están fechados en el último cuarto del siglo XVIII, cuando presumiblemente empieza a notarse el interés de ese tipo de explotación. En Ronda y Jerez además el olivar se combinaba con frutales, en otros seis casos se lo cultivaba con bellota, mientras que en La Adrada y Burguillos dos pequeños fundos de 31 y 10 fanegas lo acompañaban de moreras, lo que hace pensar en que estaba relacionado con la producción de seda. Por último, en lo que se refiere a las actividades agrícolas, se encuentran tres intervenciones de cerramiento para combinar olivar y vides; una de 188 fanegas (117,74 ha) en Jaén en 1730, otra de 172 fanegas (1013,83 ha) en Málaga en 1777 y el más conspicuo, de 2.000 fanegas (122,42 ha), en Espiel en 1773 mientras que más allá de estas consideraciones queda la gran finca de Jaén de 5.000 fanegas tantas veces mencionada. Con referencia a la realidad de Carmona, ya tomada como punto de comparación aunque solamente indicativo, Cruz Villalón señala que más del $80 \%$ de la tierra cultivada se dedicaba a cereal, el $16,5 \%$ a olivar y menos de mil aranzadas estaban a vid mientras que las tierras de cerramiento se plantaban de olivar ya fuera por la escasa fertilidad de esos suelos ya por la expansión del comercio de aceite ${ }^{44}$.

Para concluir, como demostración de la explotación de la riqueza leñosa, hay constancia de tres casos de cerramientos en Cumbres Mayores, Villalpando y Chiclana donde se plantaban encinas, bellota y leña y pinos.

Se pueden tabular los casos de peticiones según el uso que se proponía dar a los cerramientos. De 56 casos documentados, se dedicarían a:

${ }^{44}$ CRUZ VILLALÓN, 1980: 15-16. 


$\begin{array}{lcc}\text { Bellota } & 12 \text { casos o el } & 21,4 \% \text { del total; } \\ \text { Bellota y leña } & 1 & 1,8 \\ \text { Bellota y olivar } & 4 & 7,1 \\ \text { Bellota y pasto } & 5 & 8,9 \\ \text { Dehesa } & 8 & 14,3 \\ \text { Huerta } & 1 & 1,8 \\ \text { Olivar } & 13 & 23,2 \\ \text { Pasto } & 5 & 8,9 \\ \text { Sembradura } & 3 & 5,4 \\ \text { Vid y olivar } & 4 & 7,1\end{array}$

Martít5 ha calculado el valor de la producción agrícola en 1799, en la que el trigo representaba el 41,32\% del total: sin embargo el uso que se pretendía dar a los cerramientos sólo tomaba en consideración este cereal en el 5,4\% de los casos; el vino representaba el segundo producto de la agricultura con un $12,36 \%$ pero solamente en el $7,1 \%$ de los cerramiento se plantarían vides; en cambio, el aceite que era el $7,29 \%$ del producto agrícola se traduce en un $23,2 \%$ de olivares que se plantarían en los cerramientos solicitados. Y desde luego la preponderancia de la dehesa en sus varias formas - bellota, bellota y leña, bellota y olivar, bellota y pasto- $63,5 \%$ de los casos plantea un interrogante cuya respuesta podría ser la producción de aceite - bellota y olivar-o de carne para consumo y/o lana y pieles.

En su conjunto, y si se analizan los expedientes por sus fechas de presentación, no se puede alcanzar ninguna conclusión sobre tendencias temporales concretas. Dehesas y olivares aparecen como usos de explotación de la tierra difuminados en todo el período estudiado, mientras que la primera mención a los viñedos es de 1730 .

Las consideraciones hechas hasta aquí pueden servir también para reducir el interés capitalista en intervenciones productivas de carácter industrial ligadas al sector de transformación de productos agrícolas a su justa medida. De hecho se dan ejemplos de inversiones en tierras como el de don Sabino de Quevedo quien intentaba conseguir terreno realengo «infructífero sin ningún aprovechamiento por lo peñascoso del terreno y sólo podrá servir para fabricar una o dos ferrerías de que resultara grande utilidad al Real Patrimonio y común de los vecinos», de 4 fanegas de extensión por las que pagaba ocho

45 MARTÍ, 2001. Desde luego de nada vale como explicación la postura moralista de Ferrer Gorraiz quien echaba la culpa a la codicia de los labradores por «romper las dehesas y desmontar cerros» FERRER 1785: 12. 
mil reales ${ }^{46}$, o el de un comerciante de apellido extranjero, Juan-Adrián Bucq, que había construido un almacén para aceite «pegado a las paredes de dicha hacienda» de su propiedad; había usurpado una porción de comunales y la compraba en 1.102 reales $^{47}$. En 1734 en Orellana de la Sierra el marqués de Sofraga, propietario de 3.500 cabezas de merino, quería construir un lavadero en la dehesa de los Tercios de su propiedad para alcanzar mayor beneficio de su ganado, y lo conseguía tras el consabido servicio de 150 ducados $^{48}$. El último caso documentado se localiza en el Valle de Villaescusa, donde don Diego Jacinto Prieto y Bustamante solicitaba facultad de construir un molino «sobre aguas de mar» de cuatro o cinco ruedas de pan moler. El «canal» sobre el que se asentaría era de dominio público, lo que una vez más es una manera de usurpación de comunales, mas debido al interés público de la empresa se le concedía licencia pagando eso sí ciento cincuenta ducados de servicio ${ }^{49}$.

\section{Transformación de cultivos}

También es evidente el factor de transformación si no de innovación que los cerramientos representaban, considerando la relación entre el uso previsto para el predio acotado y la incidencia de ese nuevo cultivo en los usos del lugar, según indica el Catastro de Ensenada y se recoge en la tabla 8. Comparando el porcentaje de superficie dedicada al uso que se proponía para los cerramientos en relación con el conjunto de la agricultura practicada en cada lugar, se observará que el grado de innovación es inversamente proporcional al porcentaje de lo practicado localmente. Todos los valores más altos, superiores al $70 \%$ de la superficie cultivada, indican que se pretendía extender unos cultivos ya usuales; son realidades que se registran para bellota, sembradura o dehesa y se encuentran en Morón, La Rinconada, dos en Badajoz, y los otros dos más elevados, aunque ligeramente por debajo del 50\%, en Zafra y Fregenal. Estos serían las intervenciones más conservadoras, en las que se mantendrían los usos tradicionales de la agricultura local, pero la gran mayoría proponía cultivos poco usuales o incluso auténticas rarezas para lo que allí se practicaba: en Valencia de Alcántara y Usagre los cerramientos para bellota y bellota con pasto respectivamente deseaban emprender una actividad agrícola que sólo era el 39 y 32 por ciento de lo que se cultivaba en aquellos lugares, y así se puede gradualmente llegar hasta menos del 5\% de los nuevos cultivos de olivar en Bornos y Villalba del Alcor o los casos aún más extremos de Jerez de los Caballeros, Burguillos

\footnotetext{
46 AHN, Consejos, legajo 4489/85, de 24/XI/1728.

47 AHN, Consejos, legajo 4493/24, de 31/III/1732.

48 AHN, Consejos, legajo 4495/56, de 15/IX/1734.

49 AHN, Consejos, legajo 4500/34, de 13/V/1739.
} 
y Alconchel donde los cerramientos iban a introducir el cultivo de olivar unido respectivamente con frutales, moreras o bellota en lugares donde esas formas de cultivo representaban solamente el $0,81 \%, 0,44 \%$ y $0,20 \%$ de lo practicado en tiempos del Catastro de Ensenada. Dado que las peticiones eran anteriores en 10 años una y posteriores en 30 las otras dos a las contestaciones de la Única Contribución, sería poco probable que en un período de tiempo tan breve la agricultura hubiera sufrido un gran cambio; así que se trataba realmente de introducir novedades en el uso de la tierra. Analizando la relación entre cultivos propuestos y grado de usos habituales de la tierra, no se aprecia ninguna correspondencia directa, por lo que está claro que el factor innovación dependía no del cultivo sino del lugar donde se proponía emprenderlo.

La primera conclusión que se puede sacar es que los cerramientos que se fueron realizando durante el Siglo de las Luces tuvieron por efecto inmediato un paso dado en la dinámica de expropiación de los recursos comunes y un ataque a los medios materiales de vida de los campesinos menos favorecidos a la vez que representaban una ruptura con la tradicional prohibición de «acotar» predios porque ello implicaba la pérdida de los derechos de pasto en las tierras del común ${ }^{50}$. Afirmando la propiedad y el uso y disfrute individuales de los predios mediante la construcción de tapias, cercas o vallas, o sencillamente acotando una propiedad, se separaban física y legalmente del uso comunitario tierras que en adelante serían gestionadas en exclusivo beneficio de su dueño y a menudo en perjuicio de las economías de mera subsistencia de los más pobres, en una situación descrita por Bahamonde para Cantabria, o por Sanz Rosalén para la Bailía de Morella, donde la erosión de los bienes comunes representó un grave episodio de pauperización de las clases rurales inferiores, y los cerramientos significaron «un elemento clave en la política de fomento de una agricultura individualista» ${ }^{51}$ de sembradura y plantíos. En este último caso se ponen de manifiesto las tensiones especialmente con los vecinos pequeños ganaderos más que con los grandes rebaños. La política de cerramientos para plantar arbolado estaba en cierta medida coordinada con la legislación de bosques.

Por otra parte, debido a la lentitud con que se introducían las mejoras técnicas en agricultura, como hace notar Gámez Amián para Andalucía, los ce-

50 Las Cortes de Cádiz el 8 de junio de 1813 sancionarían la libertad absoluta de cercar tierras. GARRABOU y SANZ, 1985, vol. I: 54 ss. CRUZ VILLALÓN, 1990: 15, señala que en Carmona la situación «parece indicar una relación de causa a efecto entre régimen jurídico y aprovechamiento del terreno», esto es que el disfrute exclusivo de la tierra es paso imprescindible para emprender un cambio de actividad en ella. Una puesta al día sobre el estado de la cuestión en PÉREZ CEBADA y SÁNCHEZ SALAZAR, disponible en 3.udeg.edu.

51 MOLAS, 2011: 167. 
rramientos eran «el único elemento progresivo» ${ }^{52}$ en una agricultura estancada y con una disponibilidad de capitales limitada, como se concluye del escaso número de fincas adquiridas a título oneroso para cerrarlas y mejorarlas. Los datos de los expedientes también permiten concluir que los cerramientos se hacían con vistas a arrendar las fincas a más precio, participando de la subida generalizada de los arrendamientos.

Con toda la prudencia debida - conviene repetirlo - al número limitado de datos en que se apoyan estas afirmaciones, está justificado concluir que se va marcando una separación, un principio de diversificación o especialización de los cultivos, entre la ocupación agrícola mayoritaria, el cultivo de cereal, y otras más prometedoras económicamente como la producción de madera, fruta, vino y aceite. Los datos de los expedientes de cerramientos hacen luz sobre una faceta de la agricultura del siglo XVIII que representa una mentalidad emprendedora; en la casi totalidad de los casos efectuar un cerramiento significaba empezar un tipo nuevo de uso de la tierra y probablemente un uso más rentable también.

La mayor parte de las intervenciones interesaban fincas pequeñas o muy pequeñas. Luego no eran los grandes terratenientes quienes cercaban sus tierras, o, lo que es lo mismo, quienes intentaban aumentar la producción agraria, seguramente porque podían contar con el producto de una agricultura extensiva $^{53}$. Por otra parte la exigüidad de las fincas cercadas también indica la debilidad del capital dirigido hacia el campo, porque evidentemente a mayor superficie cerrada correspondía mayor esfuerzo económico.

Como los expedientes informan de que la práctica totalidad de los solicitantes tenían título de don y su gran mayoría no vivía en el lugar de los cerramientos, se puede concluir que quienes deseaban intervenir en la economía agraria estaban colocando capitales en actividades que les parecían atractivas financieramente pero no labraban directamente las tierras mejoradas. Son ejemplo las cinco solicitudes presentadas por nobles, siete de entidades religiosas y el caso de Cayo Joseph López, quien difícilmente hubiera podido labrar directamente las 414 fanegas que tenía en Usagre y las otras 1.038 en Zafra. Menos en un caso en que el arrendatario emprendía el cerramiento, se trataba de acotar tierras para arrendarlas mejor, esto es para asegurarse una renta más elevada. Es el mecanismo típico de la intervención del capital urba-

52 Para que fuera posible una política de cerramientos eficaz es preciso esperar las condiciones favorables: estructura de precios relativos de la tierra en relación con el trabajo y bajo coste del capital. ESTEVE MORA y HERNANDO ORTEGA, 2007: 175. BAHAMONDE ANTÓN, 1984. SANZ ROSALÉN, 2001. GÁMEZ AMIÁN, 1989: 84, citando a Bernal. SÁNCHEZ SALAZAR, 2001; 2005. En Cataluña se daban los Bandos Reales, facultad gubernativa de impedir al dueño el acceso a sus tierras, estudiados por PELLICER VILLALTA, 2007.

53 BERNAL, 1988. 
no en el campo, no ciertamente la huella de la actividad del «labrador honrado» de la Ilustración.

En conclusión, las peticiones de gracia merecen algunas consideraciones: su evidente exigüidad numérica, y su no menos evidente sentido de inversión capitalista que se produce en el ámbito rural pero engloba actividades productivas del sector secundario como pueden ser una herrería, un almacén comercial, un lavadero de lana y un molino. Indican intereses comerciales o industriales pero, como se ha notado anteriormente, al observar sus fechas se constata que están todas situadas en la primera mitad del siglo XVIII: desde entonces en adelante reinarían las inversiones en tierras. Mas, sea como fuere, muchas de esas intervenciones significaban en el fondo la aplicación de capitales hacia una forma nueva de actividad económica. Este sentido capitalista presenta diferentes facetas de actividad, y si es evidente que los cerramientos eran inversiones productivas, también lo es que en ningún caso tendían a mejorar técnica o tecnológicamente las labranzas. Perseguían la obtención de beneficios pero no con un trabajo directo, sino mediante el arrendamiento de las fincas mejoradas, lo que se enmarca en el aprovechamiento coyuntural de la situación de endurecimiento de los pactos agrarios propia del último cuarto del siglo XVIII.

TABLA 8. Factor de innovación en las peticiones de cerramiento: porcentaje de la superficie de tierra cultivada localmente con los mismos usos que los propuestos en las peticiones de Gracia, según la Única Contribución

\begin{tabular}{|c|c|c|c|}
\hline AÑO & LUGAR & USO PROYECTADO & \% DE USO LOCAL \\
\hline 1783 & Alconchel & Bellota y olivar & 0,29 \\
\hline 1780 & Burguillos & Olivar y moreras & 0,44 \\
\hline 1741 & Jerez de los Caballeros & Olivar y frutales & 0,81 \\
\hline 1782 & Villanueva del Río & Olivar & 1,44 \\
\hline 1742 & Jaén & Olivar & 2,72 \\
\hline 1730 & Jaén & Vid y olivar & 3,58 \\
\hline 1786 & Castro del Río & Bellota & 3,64 \\
\hline 1714 & Osuna & Bellota y olivar & 3,90 \\
\hline 1789 & Bornos & Olivar & 4,08 \\
\hline 1788 & Villalba de Alcor & Olivar & 4,24 \\
\hline 1718 & Ronda & Olivar y frutales & 4,27 \\
\hline 1720 & Morón & Dehesa & 4,95 \\
\hline
\end{tabular}




\begin{tabular}{|c|c|c|c|}
\hline AÑO & LUGAR & USO PROYECTADO & $\%$ DE USO LOCAL \\
\hline 1740 & Ronda & Bellota & 5,30 \\
\hline 1767 & Ronda & Bellota & 5,30 \\
\hline 1769 & Ronda & Bellota & 5,30 \\
\hline 1770 & Ronda & Bellota & 5,30 \\
\hline 1773 & Medina Sidonia & Bellota & 7,05 \\
\hline 1751 & Antequera & Olivar & 7,80 \\
\hline 1799 & Baena & Pasto & 8,46 \\
\hline 1722 & Dos Hermanas & Olivar & 10,40 \\
\hline 1788 & Carmona & Dehesa & 10,58 \\
\hline 1742 & Pastrana & Olivar & 11,80 \\
\hline 1732 & Guádix & Sembradura & 13,06 \\
\hline 1716 & Cumbre Mayores & Bellota & 16,21 \\
\hline 1787 & La Campana & Bellota y olivar & 17,00 \\
\hline 1775 & Medina Sidonia & Sembradura & 17,49 \\
\hline 1717 & Villalpando & Bellota y leña & 18,00 \\
\hline 1727 & Cabezas de San Juan & Dehesa & 20,56 \\
\hline 1787 & Estepa & Bellota y olivar & 22,30 \\
\hline 1728 & Cuenca & Dehesa pasto & 24,30 \\
\hline 1724 & Cala & Bellota & 29,47 \\
\hline 1789 & Usagre, Llerena & Bellota y pasto & 32,35 \\
\hline 1755 & Valencia de Alcántara & Bellota & 39,44 \\
\hline 1731 & Cumbres S. Bartolomé & Bellota y pasto & 40,15 \\
\hline 1731 & Cumbres S. Bartolomé & Bellota y pasto & 40,15 \\
\hline 1729 & Fregenal & Bellota & 41,26 \\
\hline 1789 & Chiclana & Pinar & 43,09 \\
\hline 1784 & Zafra & Bellota & 47,35 \\
\hline 1722 & Fregenal & Dehesa & 49,51 \\
\hline 1725 & Badajoz & Pasto & 71,15 \\
\hline 1738 & La Rinconada & Dehesa olivar & 71,96 \\
\hline 1719 & Morón & Sembradura & 77,84 \\
\hline
\end{tabular}


APÉNDICE. Peticiones de licencia de cerramiento presentadas a la Cámara de Castilla, 1714-1799.

\begin{tabular}{|c|c|c|c|c|}
\hline AÑO & LUGAR & SOLICITANTE & FANEGAS & USO PREVISTO \\
\hline 1714 & Osuna & Diego Fernández Piñero & 550,00 & Bellota y olivar \\
\hline 1716 & Cumbre Mayores & Convento Santa Clara & & Bellota \\
\hline 1717 & Villalpando & Francisco Manuel Cifuentes & 3,75 & Bellota y leña \\
\hline 1718 & Ronda & Diego de Morales y Ayala & 200,00 & Olivar y frutales \\
\hline 1719 & Morón & José de Angulo Topete & 600,00 & Sembradura \\
\hline 1720 & Morón & Miguel Topete & 879,00 & Dehesa \\
\hline 1722 & Dos Hermanas & Lope de Monsalve & 46,50 & Olivar \\
\hline 1722 & Fregenal & García Sánchez de Arjona & 250,00 & Dehesa \\
\hline 1723 & Lebrija & Francisco de Arriaza & 4,00 & \\
\hline 1724 & Cala & Álvaro de Castilla & 200,00 & Bellota \\
\hline 1725 & Badajoz & Conv. Sta. Catalina Mártir & $1.000,00$ & Pasto \\
\hline 1725 & Cala & Álvaro de Castilla & 36,00 & \\
\hline 1726 & Vera & Antonio Sarmiento & 615,00 & Pasto \\
\hline 1727 & $\begin{array}{l}\text { Cabezas de } \mathrm{S} \text {. } \\
\text { Juan }\end{array}$ & Pedro Antonio de Parga & 12,00 & Dehesa \\
\hline 1728 & Cuenca & Quiteria A. Salomarde & 4,50 & Dehesa pasto \\
\hline 1729 & Fregenal & Manuel Tinoco de Castilla & 200,00 & Bellota \\
\hline 1730 & Jaén & Jerónimo Ruiz & 188,00 & Vid y olivar \\
\hline 1731 & $\begin{array}{l}\text { Cumbres } \\
\text { S.Bartolomé }\end{array}$ & Lorenzo Fernández Ontañón & 65,00 & Bellota y pasto \\
\hline 1731 & $\begin{array}{l}\text { Cumbres } \\
\text { S.Bartolomé }\end{array}$ & Colegio Jesuitas & 510,00 & Bellota y pasto \\
\hline 1732 & Guádix & Fernando Pérez Pastor & 300,00 & Sembradura \\
\hline 1734 & Córdoba & Pedro de Zea y Córdoba & 115,00 & Dehesa \\
\hline 1735 & Santaella & Convento San Agustín & 180,00 & Pasto \\
\hline 1737 & Cala & Petición repetida cfr. 1725 & & \\
\hline 1738 & Jerez Caballeros & $\begin{array}{l}\text { Antonio Maraver Ponce de } \\
\text { León }\end{array}$ & 100,00 & Caza \\
\hline 1738 & La Rinconada & María de Adorna & 600,00 & Dehesa y olivar \\
\hline 1740 & Jerez Frontera & Álvaro de Valdespino & 391,00 & Bellota y pasto \\
\hline 1740 & Ronda & Francisco Rodríguez Bravo & 120,00 & Bellota \\
\hline 1741 & Jerez Caballeros & Luis de Mendoza Moscoso & 12,00 & Olivar y frutales \\
\hline
\end{tabular}




\begin{tabular}{|c|c|c|c|c|}
\hline AÑO & LUGAR & SOLICITANTE & FANEGAS & USO PREVISTO \\
\hline 1741 & Tordesillas & Capellanía Antonio de Pozo & 50,00 & Bellota y pasto \\
\hline 1742 & Jaén & Jerónimo Ruiz & $5.000,00$ & Olivar \\
\hline 1742 & Pastrana & Santiago de Arostívar & 200,00 & Olivar \\
\hline 1745 & Écija & Bernardo Aguilar Ponce León & 363,30 & \\
\hline 1745 & Motril & Rafael Luminati & 615,00 & Dehesa \\
\hline 1751 & Antequera & Marqués de Villadarias & 573,00 & Olivar \\
\hline 1751 & Jerez Caballeros & Marqués de Rianzuela & & \\
\hline 1753 & Ayamonte & Manuel Rivero & 0,25 & \\
\hline 1754 & $\begin{array}{l}\text { Puerto Santa } \\
\text { María }\end{array}$ & Juan José Reinoso y Luyando & 200,00 & Olivar \\
\hline 1755 & $\begin{array}{l}\text { Valencia de } \\
\text { Alcántara }\end{array}$ & Alonso Bayllo presbitero & 9,00 & Bellota \\
\hline 1757 & Jerez Caballeros & Marqués de Rianzuela & 4,50 & Almazara \\
\hline 1761 & Córdoba & Blasco Alfonso De Sousa & 300,00 & Pasto \\
\hline 1763 & $\begin{array}{l}\text { Sanlúcar Barra- } \\
\text { meda }\end{array}$ & José García de Lemos & 240,00 & \\
\hline 1767 & Ronda & Francisco Salvatierra Tabares & 198,00 & Bellota \\
\hline 1769 & Ronda & Alonso Holgado Díaz Medina & 144,00 & Bellota \\
\hline 1770 & Ronda & Antonio de Rivera & 350,00 & Bellota \\
\hline 1773 & Espiel & Josef Rafael González & $2.000,00$ & Vid y olivar \\
\hline 1773 & Medina Sidonia & Cristóbal Josef Collado & 170,00 & Bellota \\
\hline 1775 & Cáceres La Zafra & Marqués de Camarena & Charca & Pesca \\
\hline 1775 & Medina Sidonia & G. J. Ximénez Zurita Larrea & 376,00 & Sembradura \\
\hline 1776 & La Adrada & Francisco A. Suárez Valdés & 31,00 & Olivar y moreras \\
\hline 1777 & Málaga & Antonio Manso & 172,00 & Trigo, vid y olivar \\
\hline 1780 & Burguillos & Josef Romero quintín & 10,00 & Olivar y moreras \\
\hline 1782 & Dos Hermanas & Joaquín Cavalieri y Torres & 77,00 & Huerta \\
\hline 1782 & $\begin{array}{l}\text { Villanueva del } \\
\text { Río }\end{array}$ & Manuel de las Cuentas & 300,00 & Olivar \\
\hline 1783 & Alconchel & Conde de Villahermosa & 75,00 & Bellota y olivar \\
\hline 1784 & Granada & Congregación San Felipe Neri & $1.080,00$ & Bellota \\
\hline 1784 & Sevilla & Diego Guzmán & 600,00 & Olivar \\
\hline 1784 & Zafra & Cayo Josef López & $1.038,00$ & Bellota \\
\hline 1786 & Castro del Río & Colegio Asunción de Córdoba & 166,00 & Bellota \\
\hline
\end{tabular}




\begin{tabular}{|c|l|l|r|l|}
\hline \multicolumn{1}{|c|}{ AÑO } & \multicolumn{1}{|c|}{ LUGAR } & SOLICITANTE & \multicolumn{1}{|l|}{ FANEGAS } & USO PREVISTO \\
\hline 1787 & Badajoz & Manuel de Laguna Moscoso & 835,00 & \\
\hline 1787 & Estepa & Pablo de Traba & 288,00 & Bellota y olivar \\
\hline 1787 & La Campana & $\begin{array}{l}\text { F. Aguilar Fernández de Cór- } \\
\text { doba }\end{array}$ & 233,00 & Bellota y olivar \\
\hline 1787 & Llerena & Antonio López Espinosa & 11,00 & \\
\hline 1788 & Carmona & Alonso Rodríguez Seoane & $1.020,00$ & Dehesa \\
\hline 1788 & Villalba de Alcor & José Romero & 79,00 & Olivar \\
\hline 1789 & Bornos & $\begin{array}{l}\text { F. Alonso González Balleste- } \\
\text { ros }\end{array}$ & 200,00 & Olivar \\
\hline 1789 & Chiclana & Gregorio Collantes & 414,00 & Bellota y pasto \\
\hline 1789 & Usagre, Llerena & Cayo Josef López & Dehesa & Pasto \\
\hline 1799 & Baena & Ayuntamiento & & Pinar \\
\hline
\end{tabular}

\section{BibLiOgRAFÍA}

Allen, Robert C. La revolución en los campos, S.E.H.A. Zaragoza-Salamanca, 2004.

Alonso, Martín, Diccionario medieval español, Salamanca, Universidad Pontificia, 1986.

Amalric, Jean, «En el siglo XVIII: ¿una agricultura agarrotada?» en Bennassar, Bartolomé (ed.), Orígenes del atraso económico español, Barcelona, Ariel, 1985.

Anes, Gonzalo, «Del expediente de ley agraria al informe de Jovellanos», en García Sanz, Ángel y Sanz Fernández, Jesús (eds.), Reformas y políticas agrarias en la historia de España, Madrid, M.A.P.A., 1996.

Argemí y D'abadal, Lluis (ed.) Agricultura e Ilustración, Madrid, M.A.P.A. 1988.

Bahamonde Antón, Margarita, Tierras y prados comunales a través de las Ordenanzas de Cantabria (Siglos XVI-XIX), Santander, Tantín, 1984.

Bernal, Antonio Miguel Economía e historia de los latifundios, Espasa Calpe, Madrid 1988.

Bernal, Antonio Miguel «Antiguo Régimen y transformación social», en Antiguo Régimen y liberalismo. Homenaje a Miguel Artola, Madrid, Alianza 1994; 69-86.

Bustos Rodríguez, Manuel, «Génesis, desarrollo y cristalización de la teoría y política económica agrarias de Campomanes», Revista de la Facultad de Geografía e Historia, 4, 1989; 151-172.

Congost i Colomer, Rosa y Lana, José Miguel (eds.), Campos cerrados, debates abiertos. Análisis histórico y propiedad de la tierra en Europa (siglos XVI-XIX), Pamplona, Universidad de Navarra, 2007.

Congost i Colomer, Rosa, «Sagrada propiedad imperfecta: Otra visión de la revolución liberal española», Historia Agraria, 20, 2000; 61-93. 
Congost i Colomer, Rosa, «La "gran obra" de la propiedad» en Congost i Colomer, Rosa y Lana, José Miguel (eds.), Campos cerrados; 21-52.

Coronas González, Santos, Ilustración y derecho. Madrid, I.N.A.P., 1992.

Cruz Villalón, Josefina, Carmona 1751 según las respuestas generales del Catastro de Ensenada, Madrid, Centro Gestión Catastral, 1990.

Cruz Villalón, Josefina, Propiedad y uso de la tierra en la Baja Andalucía. Carmona, siglo XVIII-XX. Madrid, M.A.P.A., 1980.

Esteve Mora, Fernando y Hernando Ortega, Javier, «Régimen comunal y economía moral en el Antiguo Régimen. La lenta transformación de los derechos de propiedad en Madrid, siglos XV - XVIII», en Congost i Colomer, Rosa y Lana, José Miguel (eds.), Campos cerrados; 173-200.

Ferrer Gorraiz y Beaumont, Vicente, Disertación o memoria sobre el fomento y progreso de la agricultura Madrid, Imprenta Real 1785

Gámez Amián, Aurora, «¿Una o varias agriculturas en la Andalucía del siglo XVIII?» en Estructuras agrarias y reformismo ilustrado en la España del siglo XVIII, Madrid, M.A.P.A., 1989.

García Sanz, Ángel y Sanz Fernández, Jesús, «Agricultura y ganadería», en Artola, Miguel (dir.), Enciclopedia de historia de España, I, Madrid, Alianza, 1988.

Garrabou, Ramón y Sanz Ángel (eds.), Historia agraria de la España contemporánea, I, Barcelona, Crítica, 1985.

González Beltrán, José Manuel, «Precios y salarios agrícolas en Jerez de la Frontera a fines del siglo XVIII» en Aranda Pérez, Francisco José (coord.), El mundo rural en la España moderna, Cuenca, Universidad Castilla-La Mancha, 2004; 311-322.

Guerrero, Ana, «Los viajeros ingleses y la agricultura en el siglo XVIII», en Agricultura y Sociedad, 46, 1988, pp. 257-276.

IX Congreso de Historia Agraria, Bilbao, Universidad del País Vasco, 1999.

Juan y Seva, Ramón Recopilación de todas las medidas agrarias de España, Madrid, Imprenta Real, 1863.

Lara Ramos, Antonio, Hacia una historia económica de Guadix y comarca. Claves para el estudio de su realidad socioeconómica (Siglos XVIII, XIX y XX), Guadix, 1999.

Llombart, Vicent, «Una nueva mirada al Informe de Ley Agraria de Jovellanos doscientos años después», en Revista de Historia Económica, XIII, 3, 1995; 553 580 .

Llopis Agelán, Enrique, «Expansión, reformismo y obstáculos al crecimiento (17151789)», en Comín, Francisco, Hernández, Mauro y Llopis, Enrique (eds.), Historia económica de España, Barcelona, Crítica, 2002; 141 ss.

Lluch, Ernest y Argemí y d'Abadal, Lluis (editores) Agronomía y fisiocracia en España (1750-1820), Valencia, Institución Alfonso el Magnánimo, 1985.

Marcos Martín, Alberto, «Estructuras de la propiedad en la Época Moderna: evolución y variantes peninsulares», en De Dios, Salustiano (ed.), Historia de la propiedad en España, Madrid, C.E.R., 1999. 
Melón Jiménez, Miguel Ángel, Pereira Iglesias, José Luis y Rodríguez Cancho, Miguel, «Carlos II y la «cuestión agraria» en Extremadura», en Colegio Internacional Carlos III y su siglo, II, Madrid, Universidad Complutense, 1990; 895-912.

Molas, Pere, «Las Cortes nacionales en el siglo XVIII», en Escudero, José Antonio (ed.), Cortes y Constitución de Cádiz. 200 años. I, Madrid, Espasa 2011; 156171.

Muñoz de Bustillo, Carmen, «Cerramientos de tierras en Jerez de la Frontera. Testimonios de un pleito de mediados del siglo XVIII», Historia, Instituciones, Documentos, 25, 1998; 473-502.

Ortega López, Margarita, «Conflictividad social y reforma agraria en la España de Carlos III», en Estructuras agrarias y reformismo ilustrado en la España del siglo XVIII, Madrid, M.A.P.A., 1989; 663-684.

Pascual, Pere, Sudriá, Carles, «El difícil arranque de la industrialización (18401880)», en Comín, Hernández y Llopis (eds.), Historia económica de España, Barcelona, Crítica, 2002; 202-241.

Pellicer Villalta, Montserrat, «Los cercamientos de tierras en Cataluña. Fuentes para el estudio de una "revolución silenciosa" (1714-1785)» en Congost i Colomer, Rosa y Lana, José Miguel (eds.), Campos cerrados, 2007; 249-292.

Pérez Cebada, Juan Diego «Los costes sociales de los cerramientos de tierras en Andalucía Occidental» en Congost i Colomer, Rosa y Lana, José Miguel (eds.), Campos cerrados, 2007; 327-351.

Pérez Picazo, M. Teresa, «Las estructuras agrarias», en Jover Zamora, José María (dir.), Historia de España, XXX, Madrid, Espasa Calpe, 1998; 427-574.

Robledo Hernández, Ricardo, «Política reformista del régimen de tenencia de la tierra: Salamanca (1750-1808)», Estructuras agrarias y reformismos ilustrado en la España del siglo XVIII, Madrid, Ministerio de Agricultura, Pesca y Alimentación, 1989; 705-736.

Robledo Hernández, Ricardo, Economistas y reformadores españoles: la cuestión agraria (1760-1935), Madrid, M.A.P.A. 1993.

Rueda Hernández, Germán, «Las sociedades rurales y la desamortización», en Jover Zamora, José María (dir.), Historia de España, XXX, Madrid, Espasa Calpe, 1998; 575-717.

Ruiz Rodríguez, Juan Ángel, La lucha por la tierra en Don Benito a finales del siglo XVIII. Don Benito, Ayuntamiento, 2004.

Sánchez Salazar, Felipa, «Tensiones sociales en el reino de Granada finales del Antiguo Régimen: la Mesta contra propietarios de tierras y concejos con motivo de los cercados», en VII Congreso de Historia Económica, Zaragoza, 2001.

Sánchez Salazar, Felipa, «Cercados y acotamientos de tierras en Extremadura: la Real Cédula de 15 de junio de 1788», Estudios Agrosociales y Pesqueros, 207, 2005; 13-50.

Sánchez Salazar, Felipa, «Doctrinas sobre los cercados en España, siglos XVIIIXIX» en Congost i Colomer, Rosa y Lana, José Miguel (eds.), Campos cerrados, 2007; 235-248. 
Sánchez Salazar, Felipa, «Tierras municipales y extensión de los cultivos en la política agraria de la Ilustración», en Estructuras agrarias y reformismo ilustrado en la España del siglo XVIII, Madrid, M.A.P.A., 1989; 685-704.

Sánchez Salazar, Felipa, Derrota de mieses y cercados y acotamientos de tierras: un aspecto del pensamiento agrario en la España del siglo XVIII, 2002, disponible en http://www.montesdesocios.es/contenido/sanchez-salazar-f-derrota-de-miesesy-cercados-y-acotamientos-de-tierras-un-aspecto-del-pe

Santiago Bujalance, Julián, Historia de la agricultura andaluza, siglos XVIII-XXI, Sevilla, C.A.P., 2004.

Sanz Rosalén, Vicent, Propiedad y desposesión campesina. La bailía de Morella, Valencia, UNED, 2001.

Sebastián Amarilla, José Antonio «La agricultura española y el legado del Antiguo Régimen (1780-1855)», Enrique Llopis (ed.), El legado económico del Antiguo Régimen en España, Barcelona, Crítica, 2004; 147-186.

Vicent López, Ignacio María, «Dominio, consejo y conciencia en la clausura de la Junta de Baldíos», en El mundo hispánico en el Siglo de las Luces, II, Madrid, Universidad Complutense, 1996; 1331-1343.

VII Congreso de Historia Agraria, Baeza, Sociedad Española de Historia Agraria, 1995.

VIII Congreso de Historia Agraria, Salamanca, Universidad de Salamanca, 1997.

Yun Casalilla, Bartolomé, «Ingresos, formas de distribución del producto agrario y cambio social en Castilla la Vieja y León en el siglo XVIII», en Estructuras agrarias y reformismos ilustrado en la España del siglo XVIII, Madrid, Ministerio de Agricultura, Pesca y Alimentación, 1989; 481-505.

Yun Casalilla, Bartolomé, "La manzana de la discordia» en La gestión del poder. Corona y economías aristocráticas en Castilla (siglos XVI-XVIII), Madrid, Akal, 2002; 221-245.

Yun Casalilla, Bartolomé, «Las raíces del atraso económico español: crisis y decadencia (1590-1714)» en Comín, Francisco, Hernández, Mauro y Llopis, Enrique (eds.), Historia económica de España, Barcelona, Crítica, 2002; 85-119.

Recibido: $13 / 04 / 2015$

Aceptado: 21/10/2016 